Post-print of (paper) Curr. Med. Chem., 2013, 20, 751-771.

Entry inhibitors directed towards glycoprotein gp120: an overview on a promising target for HIV-1 therapy

Aida Flore and Ernesto Quesada

Received: August 14, 2012 Revised: December 03, 2012 Accepted: December 14, 20127

DOI: $10.2174 / 0929867311320060002$

\title{
Entry inhibitors directed towards glycoprotein gp120: an overview on a promising target for HIV-1 therapy
}

\author{
Aida Flores* and Ernesto Quesada* \\ Instituto de Química Médica (CSIC), Juan de la Cierva 3, 28006 Madrid, Spain \\ * To whom correspondence should be addressed. \\ Nucleosides and Analogs Research Group, Dpt. Química Médica-III, Instituto de Química Médica CSIC, \\ Juan de la Cierva, 3 E-28006 Madrid, Spain \\ E-mail address: EQ1@iqm.csic.es; aidaflores@iqm.csic.es \\ Phone: +34-91-562 29 00; Fax: +34-91-564 4853
}

This work is dedicated to the memory of our friend and colleague,

Christian G. Claessens (1969-2012).

\begin{abstract}
In spite of the unquestionable positive impact of HAART in the treatment of HIV infection, the discovery and development of novel agents directed towards other targets of the replicative cycle of the virus that differ from those targeted by the clinically approved drugs, emerges nowadays as an imperative need. The blockade of HIV entry is a highly promising strategy against the pathogen and glycoprotein gp120 is a central actor in this process. This review discusses the current status in the research of anti-HIV agents targeting specifically the envelope protein gp120. The diverse approaches devoted to the achievement of therapeutic agents against gp120 currently under study are organized and analyzed critically according to their specific mechanism of inhibition and structural features.
\end{abstract}


Key words: AIDS, Human Immunodeficiency Virus (HIV), HIV entry, attachment inhibitors, polyanions, Carbohydrate-Binding Agents (CBAs), CD4 binding site, co-receptor binding site, glycoprotein gp120. 


\section{INDEX}

1. Introduction

2. HIV entry process

2.1. Viral components of HIV-1 entry: gp120 structure and function

2.2. Entry process mechanism

3. gp120 inhibitors

3.1. Polyanionic compounds

3.2. Carbohydrate-Binding Agents (CBAs): glycans of gp120 as targets

3.2.1. Carbohydrate-Binding Proteins (CBPs)

3.2.2. Nonpeptidic CBAs

3.3. Targeting CD4 binding site on gp120

3.4. Targeting co-receptor binding sites on gp120

3.5. Small-size antibody compounds

3.6. Miscellaneous

\section{Conclusions}

\section{Introduction}

Acquired immunodeficiency syndrome (AIDS) is one of the most devastating infectious diseases in the history of mankind. Entering the fourth decade of the AIDS pandemic after the first official cases reported in 1981, it is calculated that more than 34 million people were living worldwide at the end of 2011 infected by the human immunodeficiency virus (HIV), the causative agent of the disease, and a higher number is expected in the future. Only in 2011, more than 2.5 million people became newly infected and the number of deceases from AIDS-related causes worldwide during the same year reached the dramatic figure of 1.7 million people [1]. Due to its increasing extension and the high associated mortality rate, there is no doubt that AIDS represents a global health threat and that fighting this disease remains one of the major challenges for chemotherapy in the $21^{\text {st }}$ century.

HIV is a unique and formidable pathogen. Actually, besides rapidly mutating to evade the immune system, HIV targets the cells needed to fight infection. By infecting helper T cells (specifically CD4 ${ }^{+} \mathrm{T}$ ), macrophages, dendritic and glial cells, which are all central regulators of the immune response, HIV causes a frame of severe immunodeficiency resulting in high susceptibility to opportunistic pathogens, 
thus superimposing HIV with other endemic or epidemic infections. This is a daunting challenge because in most cases the association between these infections worsens both diagnoses.

In spite of the continued expansion of the HIV around the globe, it appears that the number of people infected has been stabilized over the last few years. This is a consequence of the efforts made for the development of efficient treatments against HIV and of their spread to a larger infected population. Unfortunately, despite recent developments [2], the search for a vaccine for this devastating epidemic disease still remains as an elusive task. Furthermore, it has not been possible to develop effective microbicides to prevent the transmission of HIV [3]. However, although there is no treatment currently that fully eradicates HIV-1 infection, to date there has been 26 clinically approved drugs directed against four different viral targets (three enzyme systems involved in key steps of the replicative cycle (i.e. reverse transcriptase, protease and integrase) and the viral envelope protein gp41) and one cellular target (CCR5 co-receptor) (Table 1) [4]. Therefore, thanks to the chemotherapeutic arsenal available to date, AIDS has been converted from a fatal illness into a chronic disease in an impressively short time, barely 20 years [5], which represents a huge achievement which can hardly be parallel in the whole history of medicine as a result of concerted multidisciplinary work.

Contemporary therapy against HIV-1 is based on the so-called Highly Active Anti-Retroviral Therapy (HAART) that consists of the treatment with a combination of three or more complementary drugs which are directed against critical stages of the infectious cycle of the virus [6]. While this strategy has contributed to the slow down or even the suppression of viral replication and ultimately the progression of AIDS, strongly improving the survival of the infected patients, HAART does not manage to fully eradicate the persistence of long-term reservoirs of HIV [7]. Moreover, frequent adverse effects and drug resistance are important drawbacks after prolonged treatment [8] [9]. It should be emphasized also that HAART is highly focused on a narrow number of therapeutic targets in the HIV cycle (Reverse Transcriptase (RT) and Protease (PR), see Table 1). Despite the unquestionable success of the antiviral treatment based in drugs directed against RT and PR, the replicative cycle of HIV presents several potential targets for therapeutic actuation that have to be exploited.

As a result of all that is mentioned above, intensive efforts in the discovery of effective drugs to treat HIV must continue. Therefore, the research on novel antiretroviral drugs directed to new molecular targets in the machinery of the HIV replicative cycle or the development of compounds directed to known and validated targets but exerting their inhibitory effect through new mechanisms that differ from those employed by the clinically in-use drugs results a priority area of maximum interest in the field of HIV chemotherapy [10]. Particularly, a great interest has arisen in the development of anti-HIV agents directed towards the blockage of intrinsic viral components rather than cellular elements as this strategy would avoid the disruption of the normal function of the host cell causing toxic or side effects. In this context, a new class of anti-HIV drugs have emerged very recently directed towards the inhibition of the viral entry process. 


\begin{tabular}{|c|c|c|c|}
\hline \multicolumn{2}{|c|}{ Family of compounds } & \multicolumn{2}{|c|}{ Drug } \\
\hline \multirow{3}{*}{ Reverse Transcriptase Inhibitors } & $\begin{array}{c}\text { Nucleosides } \\
\text { (NRTIs) }\end{array}$ & $\begin{array}{l}\text { Zidovudine (AZT, 1987) } \\
\text { Didanosine (ddI, 1991) } \\
\text { Zalcitabine (ddC, 1992) } \\
\text { Stavudine (d4T, 1994) }\end{array}$ & $\begin{array}{c}\text { Lamivudine (3TC, 1995) } \\
\text { Abacavir (ABC, 1998) } \\
\text { Emtricitabine (FTC, 2003) }\end{array}$ \\
\hline & $\begin{array}{c}\text { Nucleotides } \\
\text { (NRTIs) }\end{array}$ & Tenofovir & TNV, 2001) \\
\hline & $\begin{array}{l}\text { Non-nucleoside } \\
\text { (NNRTIs) }\end{array}$ & $\begin{array}{r}\text { Nevirapin } \\
\text { Delavirdin } \\
\text { Efavirenz } \\
\text { Etravirine } \\
\text { Rilpivirin }\end{array}$ & $\begin{array}{l}(\mathrm{NVP}, 1996) \\
(\mathrm{DLV}, 1997) \\
(\mathrm{EFV}, 1998) \\
(\mathrm{ETR}, 2008) \\
(\mathrm{RPV}, 2011)\end{array}$ \\
\hline \multicolumn{2}{|c|}{$\begin{array}{l}\text { Protease Inhibitors } \\
\qquad \text { (PIs) }\end{array}$} & $\begin{array}{c}\text { Saquinavir (SQV, 1995) } \\
\text { Indinavir (IDV, 1996) } \\
\text { Ritonavir (RTV, 1996) } \\
\text { Nelfinavir (NFV, 1997) } \\
\text { Amprenavir (APV, 1999) }\end{array}$ & $\begin{array}{c}\text { Lopinavir (LPV, 2000) } \\
\text { Atazanavir (AZV, 2003) } \\
\text { Fosamprenavir (FPV, 2003) } \\
\text { Tipranavir (TPV, 2005) } \\
\text { Darunavir (DRV, 2006) }\end{array}$ \\
\hline \multicolumn{2}{|c|}{$\begin{array}{c}\text { Integrase Inhibitors } \\
\text { (IIs) }\end{array}$} & \multicolumn{2}{|c|}{ Raltegravir (RTV, 2007) } \\
\hline \multirow{2}{*}{$\begin{array}{l}\text { Entry/Fusión } \\
\text { Inhibitors }\end{array}$} & Gp41 Inhibitors & \multicolumn{2}{|c|}{ Enfuvirtide (ENV, 2003) } \\
\hline & CCR5 Antagonists & \multicolumn{2}{|c|}{ Maraviroc (MRV, 2007) } \\
\hline
\end{tabular}

Table 1. Drugs approved to date as HIV inhibitors for clinical use classified according to their target [4] (In brackets, the usual acronym of the drug and the date of approval by the FDA). 
The HIV-1 cell entry is a complex multistage process subtly regulated (see section 2.2). This process is mediated by the HIV-1 env glycoproteins gp120 and gp41, located at the surface of HIV-1 and highlighted as promising targets for drug discovery. Two recently approved drugs endorse this point. Enfuvirtide [11] targets the envelope viral gp41 protein, and Maraviroc [12] acts as a cellular CCR5binding antagonist, both preventing HIV-1 from adequately entering the host cell at the early steps of the infection. Moreover, these compounds have been demonstrated to be active against virus strains which were resistant to the previous classes of anti-HIV-1 agents used in HAART [13]. Consequently, both drugs Enfuvirtide and Maraviroc would constitute a proof-of-concept that proves viral entry as a critical step susceptible to inhibition at different levels, providing researchers with diverse therapeutic targets validated and effectives for the treatment of the HIV-1 infection.

The development of antiviral agents that target glycoprotein gp120 represents a particularly major challenge because it can be considered the very first point of contact between the host cell and the pathogen. Moreover, there is to date no clinically approved drugs directed towards gp120 in spite of the intensive efforts carried out in the research and development of gp120 inhibitors over the last years. For these reasons, this review will be focused in the different strategies targeting specifically gp120 reported to date, compiling and updating the original approaches followed in this field. Additionally, novel strategies directed to inhibit gp120 that have not been previously summarized (i.e., CBA approach) will be included in this critical review. Although excellent highlights and monographs have been published covering the overall entry inhibitors from diverse perspectives [14], there are almost no focused overviews about compounds that specifically inhibit gp120-cell receptors interactions and this overview endeavors to fill this void [15].

\section{HIV entry process}

\subsection{Viral components of HIV-1 entry: gp120 structure and function}

The mature human immunodeficiency virus HIV-1 consists roughly in two copies of a singlestranded RNA that codify the genes of the virus. These RNAs, together with a series of critical viral enzyme systems (Reverse Transcriptase (RT), Ribonuclease (RB), Integrase (IN) and Protease (PR)) are all surrounded by a conical peptidic capside. This viral nucleocapside is enclosed in a spherical lipidic envelope bilayer derived from the host cell membrane upon budding. Several virus-encoded envelope glycoproteins (env proteins) are embedded on the outer membrane, asymmetrically distributed over the external surface of the HIV-1 displayed like "spikes". Each envelope glycoprotein complex is formed by a heterodimer resulting from the non-covalent association of two proteins called gp41 and gp120. Glycoprotein gp41 adopts a transmembrane location, anchored to the viral membrane and behaving as physical support of gp120, the latter being fully located on the external surface of the HIV-1 membrane. Both gp41 and gp120 are homotrimeric proteins synthesized from a common single chain polypeptide precursor gp160, which eventually is cleaved post-transductionally yielding the mature independent env proteins. 
The structure of the glycoprotein gp120 has been determined using X-ray techniques by the crystallization of several complexes of gp120 with CD4, human antibodies or drugs [16]. Very recently it has been possible to obtain highly-resolved crystal structures of unliganded core gp120 from different HIV-1 clades [17]. Notably, all the reported bound and unbound structures resemble a common CD4bound-like state. Each gp120 monomer unit is composed of five hypervariable regions (V1-V5) and five highly conserved regions (C1-C5). It has been elucidated that gp120 is constituted by a central core consisting in two main domains: an inner and an outer domain (Figure 1). The inner domain is mainly composed by conserved regions and directly interacts with gp41; while the outer domain is mostly comprised by variable regions which are heavily glycosylated and form five variable loops by the establishment of inter-chain disulfide bonds that make up the most exterior portion of the gp120 ectodomain. The main function of these variable loops is to protect the conserved domains and to evade the immunological response from the host cell. Additionally, some sections of the variable domains have an extra important role such as V3 that is involved in the binding of gp120 to the cellular chemokine coreceptors (CCR5 and/or CXCR4). Both domains are slightly spatially separated in unliganded gp120 and come together when the viral glycoprotein gp120 attaches to the primary cellular CD4 receptor, which induces conformational changes that results in the formation of a third domain termed the bridging sheet. This domain is constituted by two pairs of anti-parallel $\beta$-sheets and plays an important role in the subsequent interaction with cellular chemokine co-receptors.

A highly remarkable feature of the HIV-1 envelope glycoprotein gp120 is the presence of a large carbohydrate component (glycan) accounting for approximately 50\% of its overall molecular weight. It has been stated that these carbohydrates are bound to the peptide part of gp120 by a variable number of $N$-glycosylation sites (between 18 and 33) through asparagine residues belonging to Asn-X-Ser/Thr motifs (where $\mathrm{X}$ is any amino acid except proline) distributed profusely along the gp120 surface [18]. Despite the genetic variation among different isolates and clades of HIV-1, N-glycosylation sites are spatially conserved giving place to a dense glycan coating that surrounds the outer surfaces of the protein [19].

The glycans located at the surface of the gp120 glycoprotein are synthesized originally by the host cells using their own glycosylation machinery and incorporated subsequently by the pathogen [20]. The structural nature of these surface carbohydrates is quite variable, consisting in a diverse array of different oligosaccharides. However, in spite of the common biosynthetic origin, a few unique features in the pattern of gp120 glycosylation emerge entirely as a result of the viral modulation of the host glycosylation pathways and allow distinguishing gp120 glycans from those of the host membrane glycoproteins. Thus, these carbohydrates have been determined to be composed derived from a common structural motif based in a pentasaccharide core formed by two $N$-acetylglucosamine and three mannose subunits $\left(\mathrm{Man}_{3} \mathrm{GlcNAc}_{2}\right.$, Figure 2) linked at the appropriate N-glycosilation sites on the polypeptide chain of gp120. This pentasaccharide core is functionalized like most of the glycoproteins of the host, producing hybrid, complex-type glycans and an unusual high level of oligomannoses (known as highmannose) that consist in the pentasaccharide core functionalized additionally with up to 9 residues of mannose [21]. Such a high density of high-mannose type glycans has never been observed on mammalian 
glycoproteins [22]. On the other hand, as previously mentioned, viral glycans form a dense, intricate and homogeneous coating spatially distributed on the surface of gp120, forming additionally tight clusters by glycan-glycan interaction that efficiently mask the peptide backbone of the protein. This is again a distinctive feature, unique and peculiar of gp120 because prokaryotic cells rarely express proteins carrying this type of dense glycans.

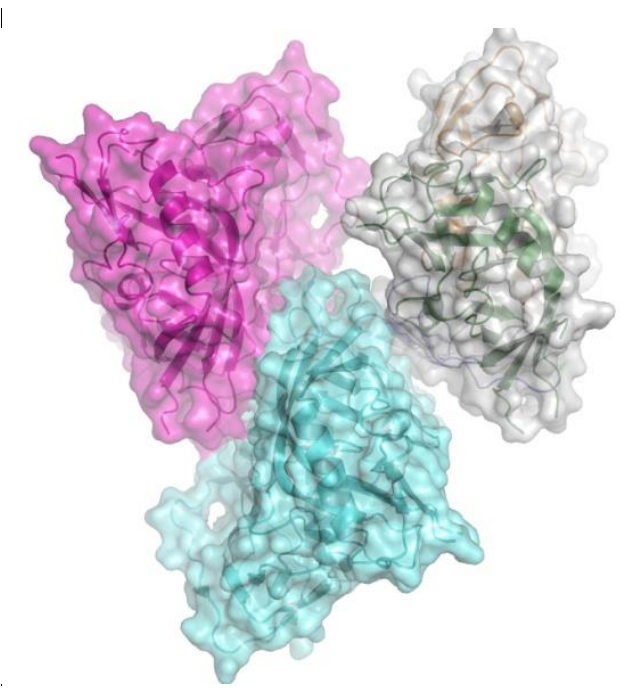

(a)

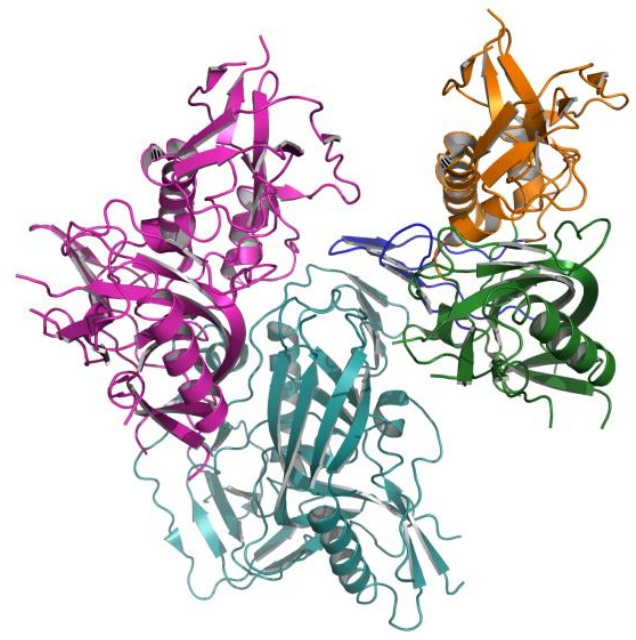

(b)

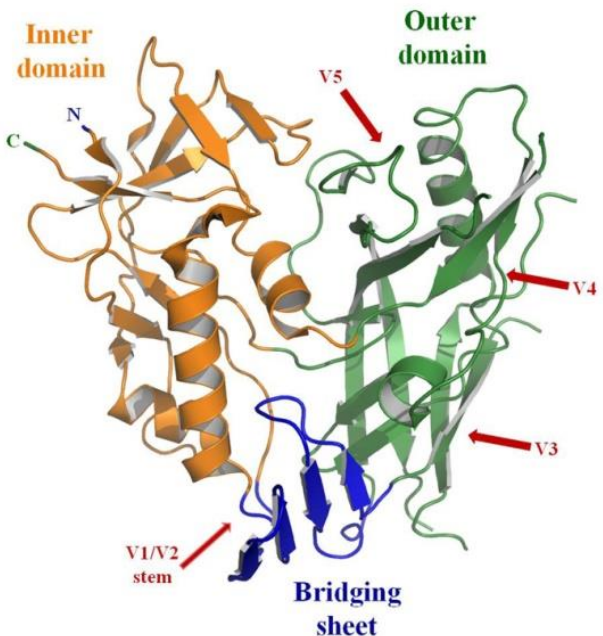

(c)

Figure 1. Structures of unliganded HIV-1 envelope glycoprotein gp120 (from HIV-1 clade B strain, YU2) [17] (a) molecular surface structures of homotrimer; (b) ribbon diagram of homotrimer; (c) detailed crystal structure gp120 core displayed as ribbon diagram. Outer domain is highlighted in green, inner domain in orange and bridging sheet in blue. The variable domains (V1-V5) are indicated by red arrows. Figures were edited and adapted from the deposited pdb data 3TGQ (DOI 10.2210/pdb3tgq/pdb). Figures were generated by Pymol program. 
The role of the gp120 glycans is critical in the infectious process as they help in the entry process into susceptible target cells and in the efficient transmission of the pathogen. Moreover, these oligosaccharides are crucial in avoiding an efficient neutralizing antibody response against HIV-1 in infected people. This is as a consequence of several factors. First, the virus has low antigenicity because the critical immunogenic epitopes located on the peptide surface of gp120 are hidden by the exceptional density of glycan array and are not easily accessible for antibody binding [23]. Secondly, the virus has a low immunogenicity because the carbohydrates surrounding the envelope spikes of gp120 only stimulate a weak antibody response. Finally, the high mutational rate of the HIV-1 virus induces continued variations and renewal of the carbohydrates of the surface preventing antibody recognition but not CD4 receptor binding. This mechanism has been developed by HIV-1 to escape immunological neutralization contributing to a high viral persistence in the face of an evolving antibody repertoire. The viral strategy has been intuitively described as an "evolving glycan shield" and amplifies the antigenic effect of relatively small sequence changes to the Asn-X-Ser/Thr-X motif [24].

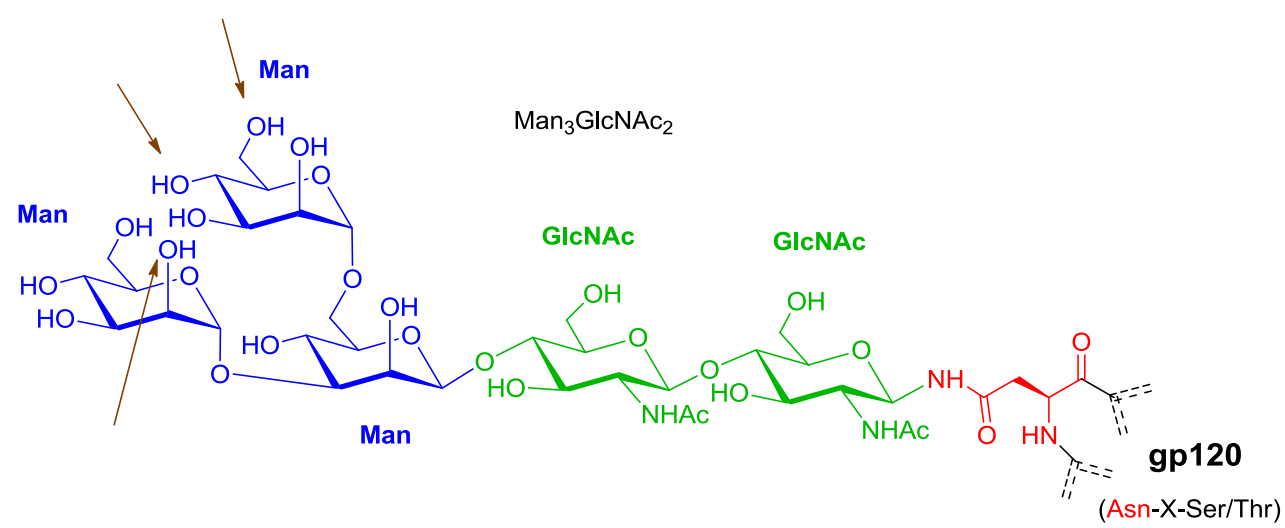

Figure 2. Structure of the common pentasaccharide core of N-linked glycans in gp120. Brown arrows indicate positions for further functionalization of the core.

The gp120 glycans have also been suggested to play an important role in viral transmission through interaction with endogenous lectins able to selectively recognize specific glycan motifs in HIV-1, such as the C-type lectin DC-SIGN, which is found on the surfaces of dendritic cells and is thought to aid in the transport of the virus to anatomical sites rich in $\mathrm{CD} 4^{+} \mathrm{T}$ cells (i.e., lymphatic nodes) [25].

Glycoprotein gp120 serves as the first point of contact with the host cell and plays a central role in the entry process mediating in the attachment to CD4 and further co-receptor binding. However, once these steps have been completed, the ultimate phase of the entry of HIV into the host cell, independently recognized as the fusion step, involves the glycoprotein gp41. Besides anchoring the gp120 subunit to the 
viral membrane, gp41 eventually directs the fusion of viral and host cell membranes, triggering the entry of the HIV capsid inside the cell [26].

The gp41 subunit of the env proteins has also been studied in great detail [27]. Like gp120, it exists as a homotrimer. Structurally, it comprises of three clearly differentiated domains, a large extracellular part (ectodomain), a transmembrane spanning anchor and an extended domain located on the inner side of the viral membrane. The functional motifs involved in fusion into the host cell have been extensively studied. Thus, four major regions are located at the ectodomain, which contains a hydrophobic, glycinerich $N$-terminal 20 residues fusion peptide (FP), a $N$-terminal heptad repeat (HR1), a $C$-terminal heptad repeat (HR2), and a tryptophan-rich region that governs the fusion. HR1 and HR2 are both domains prone to helicity, and between both heptad repeats a disulfide-bridged loop is located that docks gp120 into gp41 non-covalently. The transmembrane domain as well as the long cytoplasmic tail in gp41 modulates the conformation of external domains and subtly regulates their fusogenicity, playing both an indirect but fundamental role during the fusion. However, an exhaustive structural and functional description of gp41 is out of the scope of this report and no further details will be specified.

\subsection{Entry process mechanism}

A brief overview to the entry process is essential for the thorough understanding of the role of gp120 and its importance. The HIV-1 entry into target cells is a dynamic, complex and multi-stage process that involves at least three phases: attachment of the virus into host cells via interactions between the viral glycoprotein gp120 and cell receptor CD4, further co-receptor binding on the host cell surface and finally membrane fusion mediated by the viral gp41 transmembrane glycoprotein (Figure 3).

Despite its great complexity, the mechanism of HIV-1 entry into the host cell has been elucidated to a certain degree of detail [28]. The infection starts with the primary attachment of the virions to the target cells by unspecific interactions that permits the approach of both molecules. Then, specific interactions are established between the gp120 glycoprotein of HIV and the primary receptor CD4 expressed in the surface of a variety of immune cells such as macrophages, T lymphocytes, dentritic cells and microglial cells. This gp120-CD4 binding induces conformational changes in gp120 facilitating the formation and exposure of a chemokine co-receptor epitope located at the surface of the glycoprotein. This high affinity binding site is located in the third variable loop (V3), therefore, the virus selectivity for CCR5 or CXCR4 co-receptors is mainly defined by the amino acids sequence located in the V3 loop region in gp120. After attachment to $\mathrm{CD} 4$, the V3 region of gp120 is projected towards the target cell surface. Subsequently, it has been suggested that the $\mathrm{N}$-terminus of the co-receptor (CCR5 and/or CXCR4, depending on the virus tropism) reaches the bridging sheet at the base of V3. Further conformational rearrangements in V3 tilts this domain over the co-receptor extracellular loops that lead to the exposure of the fusion-peptide (FP) domain of gp41. The insertion of the hydrophobic $\mathrm{NH}_{2}$-terminus FP into the membrane of the target cell disrupts the lamellar organization of the host membrane phospholipids. In parallel with these events, gp41 triggers further fusogenic transformations. Thus, as the FP dart out the host membrane, it induces a folding and packing of the sensitive heptad repeat regions 
(HR1 and HR2) in gp41, creating a pre-bundle intermediate that makes the disulfide bridge of gp41 weaken its contact with gp120. The pre-bundle intermediate consequentially matures to a functional sixhelix bundle. This feature results in pulling the viral membrane close to the cellular surface and forming a viral pore that concludes with cell fusion and eventually leads to the release of the viral capsid into the cellular cytoplasm. Infection of HIV has formally started.

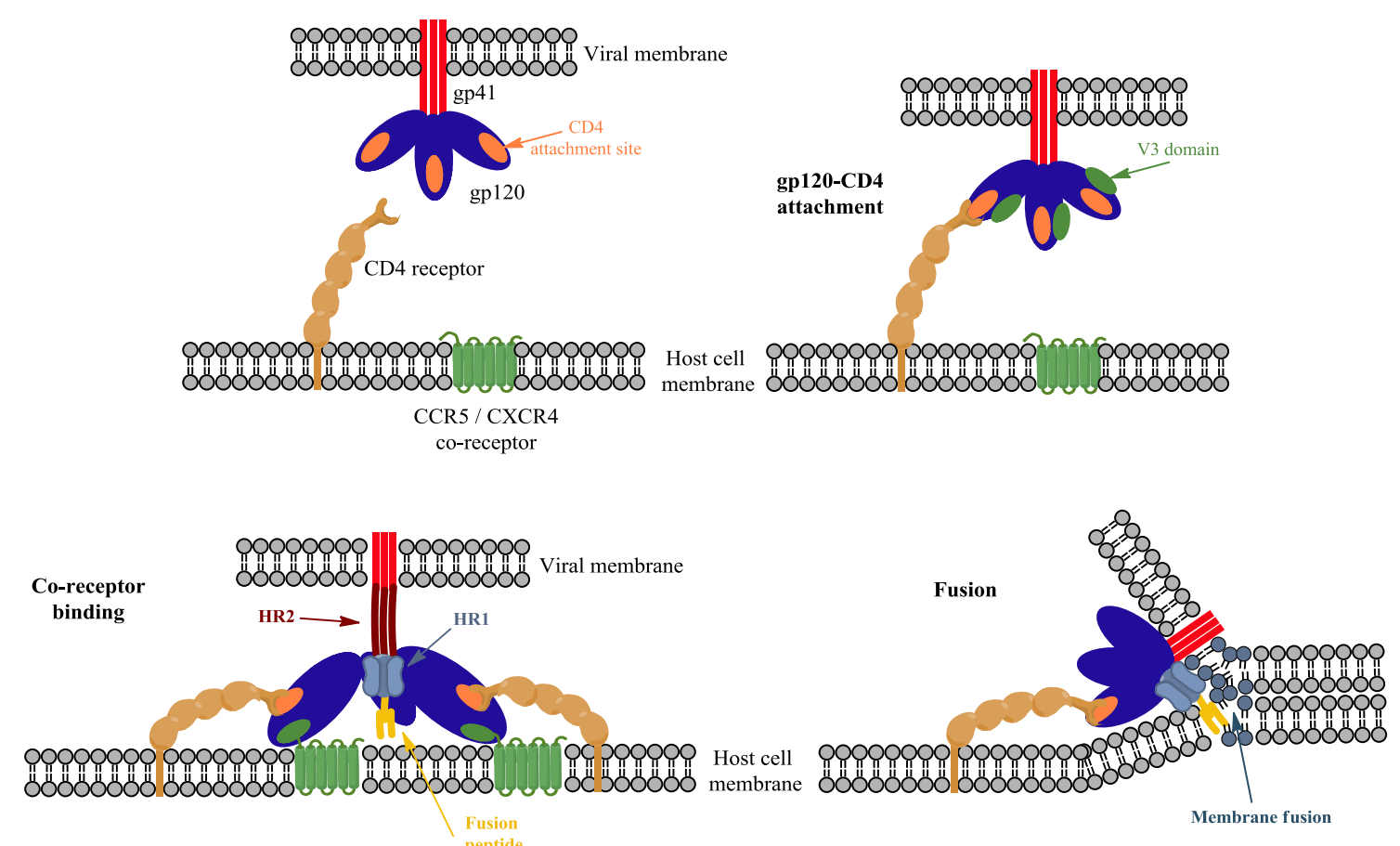

Figure 3. Schematic mechanism of the proposed entry process of HIV virus into host cell.

\section{3. gp120 inhibitors}

The different families of inhibitors of gp120 will be organized and critically described in this overview according to their specific molecular target along the structure of the glycoprotein, each one associated to a well-defined mechanism of action.

\subsection{Polyanionic compounds}

The very first step in the attachment of HIV to the target cells has been demonstrated to involve unspecific electrostatic interactions comprising of negatively charged glycoproteins located on the surface of the host-cell membrane and a series of positively charged domains of gp120. In order to avoid these interactions, polyanionic compounds have been proposed as potential HIV entry inhibitors which could bind to the glycoprotein gp120 blocking the first contact and subsequently preventing the entry of the virus into the host cell [29]. In particular, it has been reported that a series of polymeric compounds 
endowed with extensive negatively charged motifs on their structure could interact with the positively charged V3 region of gp120 in both CCR5 and CXCR4 tropism viruses. It is noteworthy that a higher affinity has been observed between polyanionic agents and CXCR4 HIV-1 viral strains, which could be explained by the presence of the more positively charged amino acids located in the V3 loop domain in this tropism, and consequently to the greater electrostatic interactions that might be established.

Given the lack of target specificity and the pharmacokinetic issues associated to the polar nature of such inhibitors, polyanionic compounds did not progress as systemic anti-HIV drugs. However, this class of agents is endowed with good properties which could be used for topical prophylactics rather than oral administration. Thus, polyanionic compounds have been considered as attractive vaginal microbicides for reducing the risk of contracting HIV since the discovery of the illness.

There are several potential polyanionic compounds microbicides described, all of them of high molecular weight with wide structural diversity and different sizes. Three of the most potent compounds reported in the literature are: sodium cellulose sulfate (1, Ushercell®), Carrageenan (Carraguard®, consisted of a mixture of $\kappa$ - and $\lambda$-carrageenan, which are linear sulfated polysaccharides extracted from naturally occurring red seaweeds), and PRO 2000 (2, a naphthalene sulfonate polymer) (Figure 4). They all are active in vitro against a wide range of HIV-1 isolates in preventing the transmission of the virus from dendritic cells to target cells in nanomolar to micromolar ranges [30] [31] [32]. Recent studies determined the safety and good properties of these polymers formulated as gels in clinical studies [33] [34] [35]. However, they finally failed facing clinical phase III trials due to their low efficacy and in some cases, to the suspicion of an increasing risk of HIV-1 infection during frequent use [36] [37] [38]. Therefore, these promising polyanionic agents were discarded as vaginal microbicides and their clinical development has been discontinued.

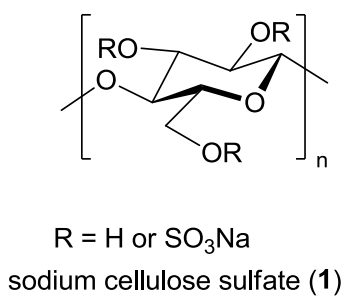

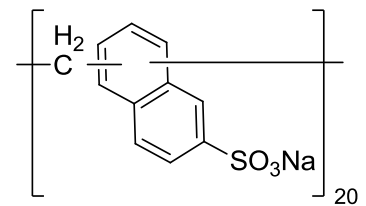

PRO 2000 (2)

Figure 4. Polyanionic polymers for HIV-1 treatment.

In an attempt to discover small molecules to avoid the problems associated during the administration of polymeric compounds, Suramin (3) emerged as the first small-size negatively charged agent directed to prevent the HIV-1 infection in vitro in human intestinal epithelial cells HT-29 (Figure 5) [39]. Suramin exploited the presence of sulfonate moieties profusely distributed on naphtalene rings further functionalized in a non-polymeric molecular structure.This polysulfonyl naphthylurea was initially proposed to inhibit the reverse transcriptase enzyme during the HIV-1 replicative cycle [40]; however, 
further studies demonstrated that this compound really neutralized the HIV infection in an early stage and blocked the attachment of gp120 with the primary cell receptor [41]. HT-29 cells express the receptor glycosphingolipid galactosylceramide (GalCer) instead of CD4. Therefore, 3 specifically binds to the conserved region of the V3 loop of gp120 blocking the gp120-GalCer interaction with an $\mathrm{IC}_{50}$ value of

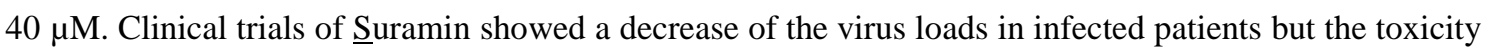
and the adverse effects observed during the treatment of these patients forced the disruption of further investigations [42]. The original results obtained with Suramin nevertheless indicated the importance of these types of structures and research in this regard has continued.<smiles>Cc1ccc(C(=O)Nc2ccc(S(=O)(=O)O)c3c(S(=O)(=O)O)cc(S(=O)(=O)O)c(S(=O)(=O)O)c23)cc1NC(=O)c1cccc(NC(=O)Nc2cccc(C(=O)Nc3ccc(S(=O)(=O)O)c4cc(S(=O)(=O)O)cc(S(=O)(=O)O)c34)c2)c1</smiles><smiles>COc1cc(N=NC2C(O)=c3c(NC(=O)c4ccc(Cl)cc4Cl)cc(S(=O)(=O)O)cc3=CC2S(=O)(=O)O)c(OC)cc1N=Nc1c(O)cc2cc(S(=O)(=O)O)cc(NC(=O)c3cccc(Cl)c3Cl)c2c1O</smiles>

FP-21399 (4)<smiles>COc1cc(/N=N/c2cc(S(=O)(=O)O)cc3cc(S(=O)(=O)O)cc(O)c23)c(OC)cc1Cc1nc(CC2=c3c(O)c(S(=O)(=O)O)cc(/N=N/c4cc(S(=O)(=O)O)ccc4OC)c3=CCC2)nc(Nc2ccccc2)n1</smiles>

ADS-J1 (5)

Figure 5. Small-size polyanionic inhibitors.

Later, Lexigen Pharmaceuticals identified compound FP-21399 (4), a bis(disulfonaphthalene) derivative structurally related to Suramin, that showed micromolar inhibition ability against HIV-1 in infected and non-infected CD4 ${ }^{+}$cells (Figure 5). It has been demonstrated that FP-21399 targets gp120 and binds to the positively charged V3 loop of the glycoprotein blocking the interaction with receptor CD4, as anticipated due to its negatively-charged nature [43]. Preclinical studies demonstrated low toxicity and no adverse reactions in animals and phase II trials showed a hint of immune response in infected patients [44]. However, further studies are still necessary to determinate its efficiency as no definitive conclusions could be established from the limited preliminary phase II trials.

Continuing the trend of designing HIV drugs based on the bis-(disulfonaphthalene) structure, Debnath and co-workers synthesized the small polyanion ADS-1J (5) closely structurally related to FP21399 (Figure 5). It must be highlighted that this compound was originally designed from computer based 
docking algorithms to potentially attach to glycoprotein gp41 and interfere with the binding to CD4 [45]. However, ADS-1J is an anionic compound and, as such, it would be expected to preferably interact with gp120 instead of gp41; therefore, there has been huge controversy about its mechanism of action over the last years and both gp120 or gp41 were proposed as therapeutic targets of 5 [46]. Very recent studies reported by Esté at al [47]. based on time-on-drug-addition and virus resistance experiments have finally clarified the inhibition step of this compound and it was concluded that it definitively behaves as a HIVgp120 inhibitor in vitro potentially via a polyanionic mechanism targeting the positively charged region of the V3 domain in gp120.

Porphyrin derivatives are a structurally different family of polyanionic compounds that have gained much attention lately for the inhibition of the HIV-1 virus. Among them, the most potent members of this new family of therapeutics so far are iron (III) porphyrins $\mathrm{Fe}^{\mathrm{III}} \mathrm{P} 1$ (6) and $\mathrm{Fe}{ }^{\mathrm{III}} \mathrm{P} 2$ (7) recently described by Kano et al. [48] (Figure 6). These porphyrins exhibited a potent antiviral activity in vitro $\left(\mathrm{EC}_{50}=0.059-1.7 \mu \mathrm{M}\right)$ and low cytotoxicities. The iron atom seems to play a capital role in the high selectivity of these porphyrins to attach to the V3 loop in gp120. Despite these promising results and attractive prospects, poor absorption into the blood stream as well as strong binding to the serum albumin in rats were observed in preclinical trials for both compounds $\mathbf{6}$ and 7, which are both seen as major drawbacks. Therefore, further enhancement of the pharmacokinetic properties should be performed for future systemic use of these anti-HIV-1 candidates, while their application as microbicides is promising and is currently under study.
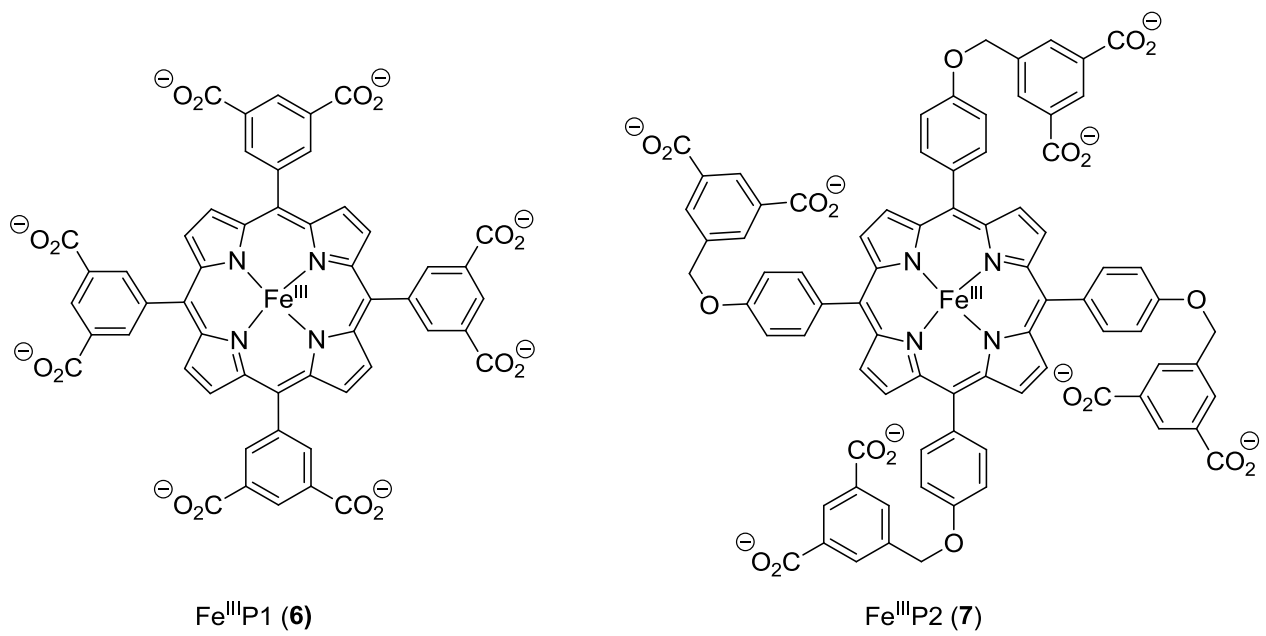

Figure 6. Metallated-porphyrin derivatives.

Sodium glycyrrhizin sulfates like $\mathbf{8}$ are another polyanionic family that emerged as novel antiHIV agents in the late 1990s able to inhibit the HIV-1 replication in vitro in the micromolar range (Figure 7) [49]. The attention focused in these compounds was owing to their amphyphylic nature (as they consist of both hydrophobic (triterpenoid group) and hydrophilic regions (sugar moiety)) and the direct 
relationship established between the ability to form micelles and the anti-HIV activity. Details about the mechanism of action of these agents have not been given but they are proposed to act in an early stage of the replication cycle of the virus. Moreover, due to their polyanionic nature it could be suggested that they act in a polyanionic mechanistic fashion.

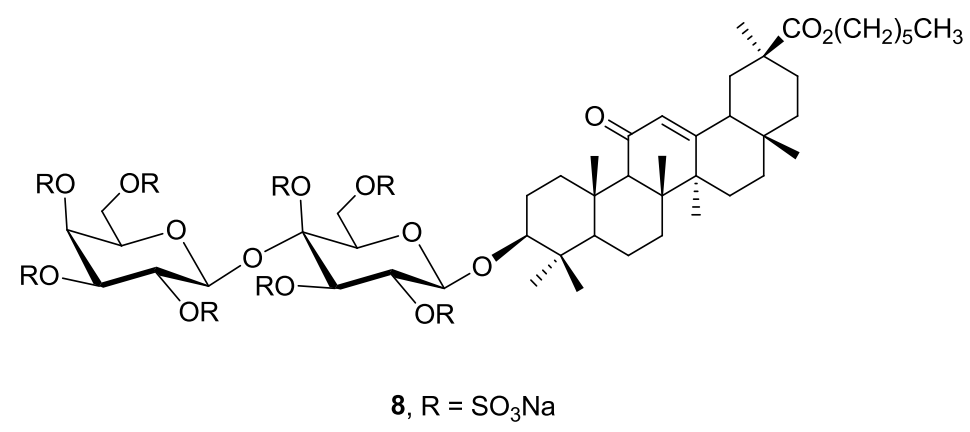

Figure 7. Sodium glycyrrhizin sulfates derivatives.

Aurintricarboxylic acid (ATA) has been found to be a potent and selective inhibitor of HIV-1 replication in vitro in MT-4 cells $\left(\mathrm{IC}_{50}=5 \mu \mathrm{M}\right)$ [50]. Originally described as a single triphenylmethanetype compound, this monomeric form readily polymerises in aqueous solution. Thus, ATA is comprised really of a heterogeneous mixture of polymeric structures schematically portrayed as 9 (Figure 8). When the polymeric mixture of $\mathbf{9}$ was separated into different fractions, it was demonstrated that exits a correlation between its potency with the average molecular weight. A similar behavior was observed when the sulfonic and phosphonic acid derivatives of ATA were studied. Thus, the higher the molecular weight, the higher the anti-HIV activity observed [51]. Moreover, under physiological conditions, ATA should be a polyhydroxycarboxylate negatively charged molecule and its inhibitory activity seems to depend on the presence of these anionic carboxylate groups, since the protected methyl ester derivatives are uniformly inactive [51b]. The anti-HIV-1 activity of the ATA fractions has been postulated to be presumably due to inhibition of gp120-CD4 interaction, targeting both viral glycoprotein as well as cell receptor, although the interaction with gp120 in the absence of CD4 binding is sufficient for anti-HIV activity.

Taking into account the information given about polyanionic compounds for the inhibition of gp120, it can be concluded that they are still far from being clinically approved for HIV-1 therapy. While polyanionic polymers have shown low efficiency in clinical trials, small size negatively charged compounds are still under development and studies regarding their pharmacokinetics properties are urgently required. However, the remarkable potent anti-HIV activity shown in several small polyanionic compounds indicates that they could have a great potential as vaginal microbicides. 


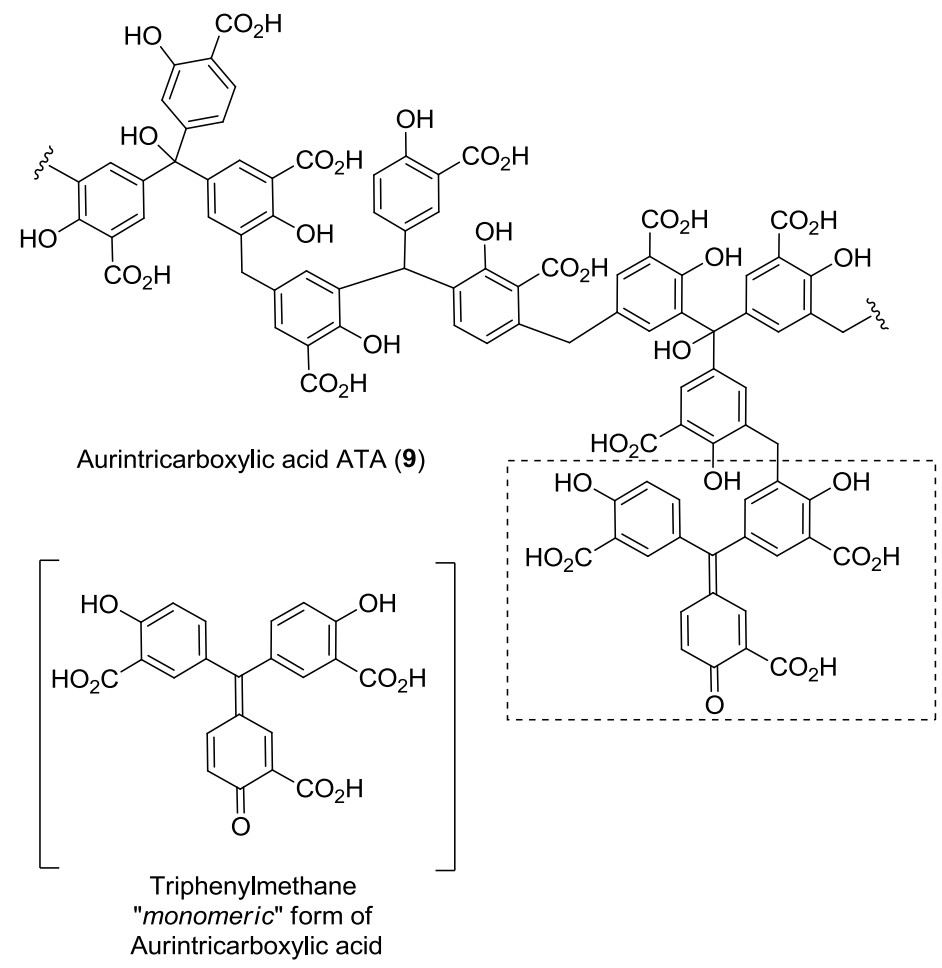

Figure 8. Aurintricarboxylic acid (ATA).

\subsection{Carbohydrate-Binding Agents (CBAs): glycans of HIV as targets}

Recently, an entirely novel strategy against human immunodeficiency virus HIV-1 has emerged proposing the glycans of the viral envelope glycoprotein gp120 as the primary molecular targets [52]. This approach is highly original as it is not the peptide portion of the protein but the carbohydrates located at the surface which constitute the goal of a new family of promising therapeutic agents described generically as Carbohydrate-Binding Agents (CBAs). CBAs are able to efficiently block HIV-1 infection and furthermore the viral transmission by exerting their activity at the early steps of the replicative cycle by binding reversibly to the envelope glycans of gp120.

An essential feature of the CBA approach is its dual nature. In a first stage, the inhibitory behavior of CBAs against HIV-1 relies on the recognition of and binding to specific sugar moieties located in the surface of gp120. Multiple non-permanent low-intensity interactions are established between the CBA and the envelope oligosaccharides that eventually originate cross-linked structures, which affect the mobility of the env proteins and prevent the conformational changes required to initiate the entry process into their target host cell. It should be also noted that binding between sugars and CBAs might be advantageous as they can target multiple HIV strains and tropisms sharing a similar carbohydrate array. 
On the other hand, it is expected that long-term therapeutic pressure due to CBA forces the virus to mutate, which results in the emergence of drug resistance. Globally, HIV-1 selects for virus mutant strains which present deletions of $N$-glycosylation sites [53], which change the glycosylation pattern of gp120 and could produce a less dense glycan shield. This feature makes more accessible previously hidden critical immunogenic epitopes, triggering an enhanced recognition and further eradication by neutralizing antibodies of the innate immune system. In this sense, Reitter et al. [54] have proved in vivo that mutant simian immunodeficiency virus (SIV) strains lacking only two $N$-glycosylation sites in their external envelope protein show a marked increase in antibody formation and a considerable decrease in viral load. A very recent contribution asserted that occluding mannose moieties in HIV-1 monomeric gp120 can improve the humoral immune response to this protein in mice [55]. Moreover, it has been reported that glycan deletions in the HIV-1 gp120 V1/V2 domains severely compromise viral infectivity and sensitize the mutant virus strains to carbohydrate-binding agents [56]. Furthermore, some specific $N$ glycosylation sites are indispensable for efficient viral entry (such as $\mathrm{Asn}^{260}$ ) [57]. Thus, a resistance pattern directed to the elimination of $N$-glycosylation sites of gp120 could be of interest in enhancing immunosuppression of the pathogen.

This depicted dual mode of action is unique and makes CBAs a conceptually novel class of antiHIV-1 agents that merges a direct chemotherapeutic action that induces for an unusually specific and selective drug resistant profile, which eventually could trigger the immune system to recognize previously hidden epitopes of the virus. Furthermore, CBAs prevent not only virus infection of susceptible cells, but also inhibit specific interactions between viruses and lectins of the immune system that lead eventually to the formation of syncytia that are used by the virus for transmission between persistently HIV-infected cells and uninfected lymphocytes This may in turn result in the more efficient elimination of infectious HIV-1.

It must be noted that the CBA strategy could also be directed against other glycan-containing enveloped viruses [58]. In fact, it has been recently demonstrated that CBAs, including several plant lectins and the non-peptidic small-size antibiotic Pradimicin A (see section 3.2.2. below) efficiently prevented hepatitis $\mathrm{C}$ virus (HCV) and HIV-1 infection of target cells by inhibiting the viral entry through their interaction with viral envelope-associated glycans [59], which may represent an attractive new option for therapy of HCV/HIV co-infections.

The term CBA was introduced by Balzarini and currently conceptually describes a heterogeneous series of compounds with carbohydrate-binding capacity that comprise a broad and structurally diverse functional class of agents including both macromolecular Carbohydrate-Binding Proteins (CBPs) as well as naturally-occurring or synthetic, non-peptidic, small-size CBAs. [53c] 


\subsubsection{Carbohydrate-Binding Proteins (CBPs)}

Several examples of naturally occurring Carbohydrate-Binding Proteins (CBPs) exists in the specialized literature whose anti-HIV activity have been reported with potencies as low as the picomolar range [60]. Among them, it must be highlighted a wide, heterogeneous family of high-molecular weight proteins generically called lectins. Lectins can be derived from a variety of species in nature, including prokaryotics, sea corals, algae, fungi, higher plants, invertebrates and vertebrates. All of them share a common mechanism of action against HIV-1 based on the ability to bind to specific carbohydrate motifs present in gp120 in a highly selective fashion. However, in spite of their potential, only a few of them have been validated as candidates for clinical studies. In this review, we will overview a few representative examples of CBPs able to bind glycans of gp120 and neutralize HIV-1.

The best known and most studied CBP with remarkable activity against HIV-1 is Cyanovirin-N (CV-N). CV-N recently attracted great interest because of its broad range of antiviral activity in most laboratory HIV-1 $\left(\mathrm{EC}_{50}<1 \mathrm{nM}\right)$ and HIV-2 $\left(\mathrm{EC}_{50} \geq 2 \mathrm{nM}\right)$ strains. It has been shown its ability to inhibit HIV infection in ectocervical human explants with remarkable selectivity [61]. Actually, CV-N is the only lectin so far tested in in vivo transmission models and its potential as a microbicide has been positively evaluated in macaque models [62]. This $11 \mathrm{kDa}$ lectin was first isolated from the cyanobacteria Nostoc ellipsosporum and consists of a single 101 amino acid chain [63]. It blocks HIV entry by specifically binding to terminal high-mannose oligosaccharides containing Mana(1-2)Man motifs, located predominantly in the $\mathrm{C} 2-\mathrm{C} 4$ regions of the viral glycoprotein gp120 [64]. In preclinical studies, formulated as a microbicide in the form of a vaginal gel for the prevention of sexual transmission of HIV infection, CV-N demonstrated no cytotoxicity or noticeable adverse effects. However, in spite of its potent antiviral activity, safety issue concerns were recently raised about its use as it has been demonstrated that it induces the expression of chemokines that eventually reached a stimulatory activity in PBMC cultures [65]. Additionally, Buffa et al. [66]. corroborated that CV-N produces some mitogenic effect in a time-dependent fashion if the exposure to the microbicide exceeds of $24 \mathrm{~h}$. Due to these drawbacks, preclinical studies on CV-N have been discontinued.

Microvirin (MVN) is a novel $12.7 \mathrm{kDa}$ lectin comprised of a 108 amino acids sequence recently isolated from the cyanobacterium Mycrocystis aeuriginosa [67]. It is related to CV-N, exhibiting a similar three-dimensional CV-N-type fold.[56b] It also exhibits specificity for Mana(1-2)Man motifs, the disaccharide unit that commonly terminates the arms of the high-mannose $N$-linked oligosaccharides in gp120 like CV-N does. Thus, MVN has become a more promising candidate for clinical studies with a remarkable anti-HIV-1 activity, comparable to that reported for CV-N but exhibiting a much higher safety profile [68].

Griffithsin (GRFT) is another lectin recently isolated from seaweed (Griffithsia sp.) [69] with a molecular weight of $12.7 \mathrm{kDa}$ and a sequence of 121 amino acids [70]. Structurally, GRFT adopts an active domain-swapped dimeric $25 \mathrm{kDa}$ form and each monomer has three almost identical carbohydratebinding sites that bind oligomannose glycans, targeting specifically terminal mannose residues found on 
high-mannose cores. GRFT is to date the most potent anti-HIV algal lectin described so far, showing activity against both HIV-1 and HIV-2 laboratory strains with $\mathrm{EC}_{50}$ values in the picomolar range. GRFT showed also potent antiviral activity against different HIV-1 clade clinical isolates and it exhibited a potent inhibitory capacity when tested in ex vivo cervical explants models. Recently, Férir et al. [71] combined GRFT with the nucleotide reverse transcriptase inhibitor Tenofovir, the CCR5 HIV co-receptor antagonist Maraviroc and the gp41 fusion inhibitor Enfuvirtide and all combinations were synergistic against HIV-1 clade B and clade C isolates in PBMCs and in CD4 ${ }^{+}$MT-4 cells. It has been also demonstrated that GRFT can be used in combination with other CBPs that recognize multiple and often distinct glycan structures on the HIV envelope gp120 and therefore do not necessarily compete with each other's glycan binding sites. These combinations showed synergistic activity against HIV-1 and available information to date is encouraging for the use of paired CBA combinations in topical microbicide applications to prevent HIV transmission [72]. Currently, GRFT is proposed as a candidate microbicide agent due to its great potential [73].

In a recent contribution, LiWang and co-workers [74] analyzed the role of the three individual carbohydrate-binding sites (CBS) in GRFT. Thus, a series of mutations were induced in the protein led to alter the individual CBS and the mutated variants of GRFT were studied by NMR and their binding affinity for gp120 glycans quantified by Surface Plasmon Resonance (SPR). Modification of any individual CBS on GRFT reduced binding of the protein to mannose, with a near-complete loss of binding by the triple mutant which alters simultaneously all the CBS. The single CBS point mutants of GRFT were significantly less able to inhibit viral infection, exhibiting a loss of HIV inhibitory potency (up to 1900-fold) compared to the wild-type protein.

In a meritorious attempt to simplify the large structure of GRFT, Ruchala et al. [75] recently identified Grifonin-1 (GRFN-1), a novel 18-residue peptide that exhibited remarkable anti-HIV-1 activity. This oligopeptide is derived from a trio of homologous $\beta$-sheet repeats that comprise the motifs responsible for the carbohydrate binding of the parent protein GRFT, and by extension, of its biological activity. Like its parent protein, GRFN-1 bound viral glycoprotein gp120 via the $N$-linked glycans on its surface as demonstrated by SPR experiments but with a 6-fold smaller molecular size. Its low toxicity, limited secondary effects and remarkable activity against both CCR5 and CXCR4 HIV-1 strains together with its relatively small size suggest that GRFN-1 and/or related derivatives may have therapeutic potential for further development as HIV-1 entry inhibitors for topical (microbicide) or systemic applications.

Globally, CBPs could be considered a novel and unique family of anti-HIV chemotherapeutic agents. Therefore, extraordinary efforts have been made into the identification of new lectins as well as into the achievement of a deep understanding of their functions and of the precise mechanism of their association with specific carbohydrate ligands. However, in spite of this enormous potential, particularly as microbicides, lectins still exhibit certain disadvantages associated to their protein nature and high molecular weight. They have intrinsically unfavorable properties such as complex production and difficult purification in large scale, high manufacturing costs, poor or any oral bioavailability, low stability (susceptible to proteases) and pose potential risks for initiating unfavorable immune responses or 
secondary effects. Hence, their development and use as suitable drugs may be compromised. Therefore, nowadays there is increasing interest in the search for synthetic low-molecular weight carbohydratebinding agents (CBAs) behaving as "lectin-mimetics", capable of acting through a similar mechanism to that of the natural lectins but without their associated limitations.

\subsubsection{Nonpeptidic CBAs}

In the last decades, the development of synthetic ligands directed to the selective recognition of carbohydrates in water has emerged as a challenge for chemists [76]. Mimicking the interaction and binding motifs observed in the protein-carbohydrate complexes (non-covalent interactions such as hydrogen bonding, $\mathrm{CH}-\pi$ interactions, etc.), it has been possible to roughly establish the molecular basis that might assist in the design of artificial carbohydrate receptors [77]. However, the reported artificial carbohydrate receptors have only been rarely studied as antivirals in the CBA strategy context. In contrast with the huge amount of literature available on CBPs (molecular weights ranging between 9 and $50 \mathrm{kDa}$ ), there are only a few reports on non-peptidic small-size CBAs endowed with antiviral activity.

In this respect, a few compounds belonging to the Pradimicin/Benanomicin families of antibiotics behave like the above-mentioned lectins. Originally developed as antifungal agents, Pradimicins are secondary metabolites based on a structure of benzo[a]naphtacenequinione containing a pattern of substitution that include amino acid residues and a monosaccharide/disaccharide core located at the periphery of the molecule (Figure 9). Interestingly, Pradimicin A (PRM-A, 10, Mw = 895), isolated from the actinomycete Actinomadura hibisca [78] exhibited a selective inhibitory activity in cell cultures against a variety of HIV-1 clades regardless of the tropism of the virus at a low micromolar range [79]. The outstanding aspect of PRM-A is related to its mechanism of action, as its antiviral activity can be ascribed to the recognition of terminal D-mannopyranosides moieties of gp120 in a $\mathrm{Ca}^{2+}$-dependent manner, blocking the entry process of HIV-1 into the host cell in a similar way to that described for lectins. Very recently, solid-state studies performed on PRM-A and BMY-28864, a water soluble analogue of PRM-A [80], provided direct experimental evidence that allowed for the proposal of a model of binding in which the amino acid residue of PRM-A is the main binding region through coordination with the calcium ion and involving also rings $\mathrm{A}, \mathrm{B}$ and $\mathrm{C}$ of two units of the antibiotic, leading to a $\left[(\mathrm{PRM}-\mathrm{A})_{2} / \mathrm{Ca}^{2+} /\right.$ Mannose] complex [81]

On the other hand, PRM-A has been found to exhibit the expected mutational pattern (selecting for $\mathrm{N}$-glycosylation deletions) and good resistance profile, two of the crucial lectin properties. However, during preclinical trials, one of the main drawbacks of PRM-A was its remarkable poor aqueous solubility. To circumvent this limitation, Pradimicin-S (PRM-S, 11) [82], a Pradimicin-A analogue that contains an extra negatively charged 3-sulfated glucose in its structure obtained by a related microorganism (Actinomadura spinosa), was evaluated (Figure 9). This analogue behaves quite similarly to PRM-A in terms of antiviral activity, glycan recognition and drug resistant-induced profile but with better pharmacokinetic properties, allowing not only its formulation as a microbicidal agent but also for potential systemic use. Hence, it is considered a good candidate for preclinical and clinical studies. 
A very recent contribution due to Bewley and co-workers [83] took advantage of the increased solubility of PRM-S to study its assembly and carbohydrate recognition under physiological conditions. Thus, by using an integrated approach that included NMR, analytical ultracentrifugation, SPR and viral neutralization assays, authors conclusively demonstrated that PRM-S is able to form discrete $\mathrm{Ca}^{2+}$ dependent oligomers that, additionally, show extremely high selectivity for the mannotriose core structure $\operatorname{Man} \alpha 1-6(\operatorname{Man} \alpha(1-3)$ Man that is a structural motif present in all high-mannose oligosaccharides. More importantly, this study is complementary to other recent contributions [80] [81] and could contribute to reveal the requirements for carbohydrate recognition by small molecules that may could be used in the future design of novel synthetic CBAs based on the Pradimicin family of compounds.

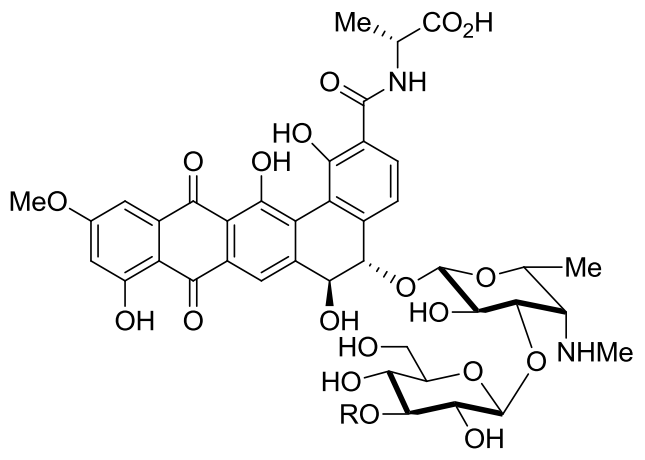

PRM-A (10), $\mathrm{R}=\mathrm{H}$ PRM-S (11), $\mathrm{R}=\mathrm{SO}_{3}{ }^{-}$

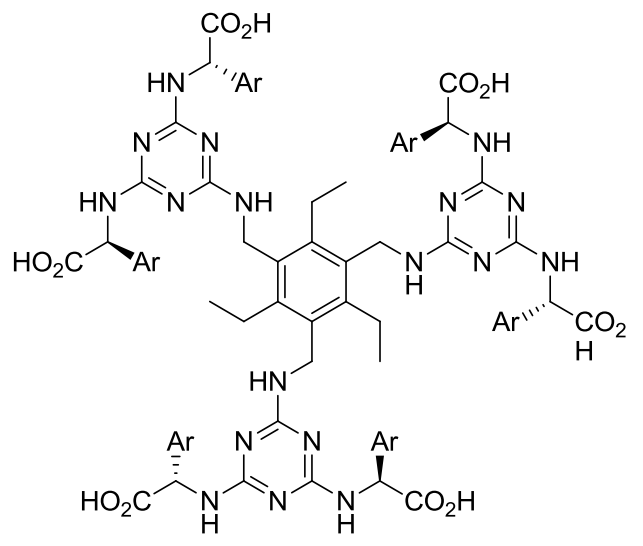

13

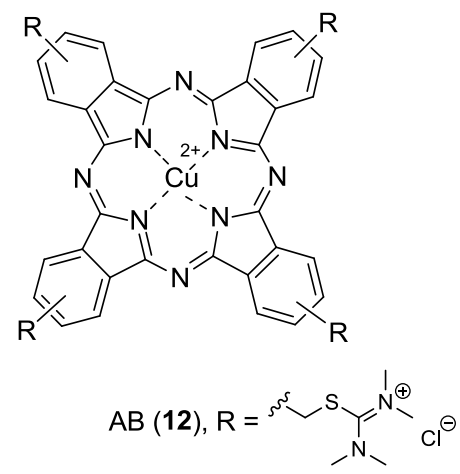

Figure 9. Structures of potential small-size synthetic carbohydrate-binding agents.

Recently, Alcian Blue (AB, 12), a phtalocyanine derivative, has been also described to inhibit the infection of a wide spectrum of HIV-1 strains in various cell cultures through a proposed mechanism involving the reversible binding to $N$-linked glycans of gp120 (Figure 9) [84]. Prolonged treatment with $\mathrm{AB}$ resulted in the selection of mutant virus strains in which several $N$-glycosylation sites of gp120 have been deleted. In this respect, $\mathrm{AB}$ closely mimics the antiviral mechanism of action and resistance profile of the plant and prokaryotic lectins. This is the first reported fully synthetic molecule that behaves like a CBA, which has a great conceptual significance. However, although AB undoubtedly targets the glycans on the envelope of HIV-1, this may not be its sole mode of antiviral activity. It is remains currently 
unclear which is the specific sugar/oligosaccharide that $\mathrm{AB}$ targets in the glycan array of gp120 and whether its antiviral activity could be also associated to other complementary interactions with molecular targets which play a direct or indirect role in the entry process of HIV. Further studies should be performed to clarify these subjects.

In 2011 Pérez-Pérez et al. [85] reported a new family of synthetic small-size CBAs based on a 1,3,5-triazine central core functionalized with aromatic amino acids which were differently branched (monomeric, dimeric and trimeric species) and were designed to mimic interactions that lectins establish with gp120. The best results were observed for trimeric compounds of general structure 13 (Figure 9). These molecules were shown to be active in the micromolar range $\left(\mathrm{EC}_{50} \sim 20 \mu \mathrm{M}\right)$ against diverse HIV isolates in vitro in CEM T-cell lines and no cytotoxicity was observed $\left(\mathrm{CC}_{50}>250 \mu \mathrm{M}\right)$. It must be highlighted that monomers were inactive against HIV replication and dimers exhibited only moderate activity, while the trimeric series were the most active compounds of the series. This clearly shows that the introduction of several ligand subunits in synthetic CBAs could compensate for the lability of the individual non-covalent bindings with the carbohydrates by the establishment of concomitant multiple interactions (multivalency [86]), as usually observed in lectins [61c] [87]. Surface Plasmon Resonance (SPR) studies verified that $\mathbf{1 3}$ inhibited the HIV-1 infection in an early step of the replicative cycle by binding to gp120, presumably due to interaction with surface carbohydrates; however, the exact mechanism of action is still under investigation.

These findings prove that CBAs with non-peptidic nature and low molecular weight able to reversibly bind to carbohydrates located at the surface of gp120 can exert a similar therapeutic effect to that exhibited by CBPs. This may have important repercussions as it provides both an encouraging proofof-concept and a rational basis for the design and further exploration of this potential class of chemotherapeutics. Further investigations are needed to reveal whether or not these compounds are able to block HIV-1 infection in vivo.

Another strategy which has been used for the design of synthetic CBAs involves the exploitation of non-natural bonding interactions as an alternative to the low-intensity noncovalent binding mimicking the natural lectins. This approach fundamentally relies on the reaction between cis-diols (profusely observed in the surface carbohydrates in gp120) and boronic acids or derivatives that eventually give cyclic structures such as boronates [77a] [88]. Over the past years, a number of research groups have attempted to develop synthetic carbohydrate receptors that could be selective for the recognition of cellsurface oligosaccharides with therapeutic potential (boronolectins) [89].

A practical strategy in this field exploits the attachment of multiple carbohydrate ligand motifs to oligomeric or polymeric backbones specifically for binding to glycans of gp120. In this regard, a recent contribution is due to Kiser et al. [90], who described a series of water-soluble polymeric structures including several benzoboroxoles as potential carbohydrate ligands. It has been stated that benzoboroxoles are able to bind to terminal nonreducing hexopyranoside residues, which are structurally similar to those present in high-mannose and complex-type $N$-linked glycans of gp120. More importantly, the interaction takes place in neutral aqueous environments. While benzoboroxole groups independently 
showed weak affinity for gp120 as demonstrated by SPR studies, the incorporation of this small ligand core molecule into oligomeric backbones created polyfunctionalised structures which strongly increase the affinity due to a multivalent effect. Thus a $25 \%$ mol benzoboroxole-functionalized polymer exhibited a moderate activity $\left(\mathrm{EC}_{50}=15000 \mathrm{nM}\right)$ while a $75 \%$ mol polymer increased its activity against HIV-1 to a nanomolar range $\left(\mathrm{EC}_{50}=11 \mathrm{nM}\right)$. These polymers demonstrated a broad spectrum of activity (against all viral strains and both co-receptor tropism) and similar efficacy in vitro as $\mathrm{CN}-\mathrm{V}$ and no noticeable cytotoxicity was observed after exposure to human vaginal cell lines for $24 \mathrm{~h}$. The mechanism of action is still not completely clear but it has been hypothesized that they can prevent binding of gp120 to either receptor CD4 or co-receptor CCR5 through covalent attachment to sugars present at the surface of the patogen's env gp120 protein. Interestingly, as lectins, these compounds demonstrated selection for mutant HIV-1 strains that contain deleted $N$-glycosylated sites on the envelope of gp120, supporting additionally a CBA-type mechanism of action.

The great potential of these compounds impelled Kiser and co-workers to extend the study [91]. Recently, high molecular weight benzoboroxole-functionalised polymers demonstrated antiviral activity that rises with increases in ligand density, endorsing that multivalence strongly improves activity. The highest activity was seen with a $382 \mathrm{kDa}$ polymer $\left(\mathrm{EC}_{50}=1.1 \mathrm{nM}\right.$ in CEM cells). However, the larger polymers showed poor aqueous solubility. In order to overcome this problem, a co-polymer containing sulfonic acid groups $(10 \% \mathrm{~mol})$ was synthesized and this increased 100 -fold the polymer solubility while maintaining activity in the same range (1-4 nM, similar to CV-N). Mechanistically, it has been proposed that the polyanionic polymer backbone would first establish unspecific electrostatic interactions with the positively charged V3 loop of gp120 (such as polyanionic agents, see section 3.1.), thereby facilitating further covalent interactions between the benzoboroxole and the glycans on gp120. Although the molecular weight of these polymers is comparable to that of the proteins, they endow remarkable advantages over CBPs such as practical and affordable production, broad-spectrum activity and ease of formulation. Therefore, these polymers may act as potential microbicides.

\subsection{Targeting CD4 binding site on gp120}

One of the most obvious and straightforward ways to prevent the HIV infection is to inhibit the binding of the virus to its primary receptor on the host cell. Thus, compounds that could interfere in the CD4 binding site in gp120 would be attractive candidates to block HIV entry process and represent the most important group of gp120 HIV inhibitors currently under study. The huge interest in these anti-HIV agents is also given to the absolute functional conservation of the CD4 binding site in gp120 among all isolates of HIV-1 and it has been hypothesized to be a site less prone to resistance-conferring mutations [92].

Soluble versions of the receptor CD4 (sCD4) were first analyzed as candidates for HIV entry inhibitors to block the gp120-CD4 attachment. The free recombinant protein sCD4 exhibited potent inhibitory activity against HIV-1 laboratory strains [93]. However, in vivo experiments revealed that SCD4 was rapidly removed from the peripheral blood and was not active enough to decrease viral loads in a set 
of HIV-1 infected patients [94]. In order to improve their pharmacokinetic properties and efficacy, several CD4 mimetics emerged as potential HIV-1 therapeutics. Among them, oligomeric CD4-IgG fusion proteins gained much consideration, such as PRO 542, which merges human immunoglobulin IgG2 and HIV-binding domains of CD4. It showed potent neutralizing and antiviral activity in vitro and ex vivo, reaching phase I/II trials [95]. Simultaneously, approaches based on the design of soluble recombinant CD4 proteins presenting amino acids mutations in specific sites or small amino acid peptides mimicking the CD4 are very significant as these agents are able to enhance the efficacies of gp120-targeted therapies and env-based immunogens [96]. However, in the recent years more attention has been paid to the identification of small-molecule inhibitors that prevent the binding of gp120 to CD4 receptor for the treatment of HIV-1 and many efforts have been directed to identify new non-peptidic low molecular weight agents.

A detailed understanding of the interaction between gp120 and CD4 has helped to design small size CD4 mimics. A significant development was the elucidation of a resolved X-ray crystal structure of gp120-CD4 complex that exposed in high detail the presence of a hydrophobic cavity in the interface of CD4 and gp120 which is formed by elements of the major domains and bridging sheet of gp120, and is occupied by a single CD4 aromatic residue, a phenylalanine located in position $43\left(\mathrm{Phe}^{43}\right)$ [17]. This deep depression has been referred to as the $\mathrm{Phe}^{43}$ cavity. Surrounding it, there are positively charged residues that make direct contact to CD4 but have a minor contribution to the gp120-CD4 interaction. Hence, compounds that target the $\mathrm{Phe}^{43}$ cavity have been suggested as desirable drug candidates that inhibit HIV1 by blocking the CD4-gp120 attachment.

The first promising small molecule described in the literature able to interfere in the gp120-CD4 receptor interaction was BMS-378806 (14) (Figure 10), an azaindole derivative discovered by a BristolMyers Squibb team [97]. The interest of this candidate was owing to its good oral bioavailability and excellent safety profile together with a potent antiviral activity in laboratory cells cultures. However, during phase I clinical trials it showed an inadequate plasma exposure in healthy human volunteers. Due to this drawback, development of BMS-378806 was discontinued and alternatively detailed structureactivity studies (SAR) were performed in order to find a better candidate for the HIV-1 treatment based in this lead compound [97b] [98].

In this context, BMS-488043 (15) containing a 7-azaindol core emerged as a new generation derivative of the parent compound $\mathbf{1 4}$ with an analogous mechanism of action [99]. It presented enhanced in vitro antiviral activity improved to the nanomolar range and a better in vivo pharmacokinetic profile, such as a longer half-life $\left(t_{1 / 2}\right)$ and better permeability in the gastrointestinal tract (Figure 10) [100]. Despite these improvements, its oral administration was still limited to both high doses and the requirement of a high-fat meal in order to reach enough plasma levels in infected patients. A practical solution to this problem was recently proposed by Kadow et al. [101] using a prodrug approach. Thus, BMS-488043 was formulated as its phosphonooxymethyl lysine salt, BMS-663749 (16) (Figure 10). This prodrug was effective in delivering the parent drug and it was rapidly absorbed in plasma, overcoming the problems related to $\mathbf{1 4}$. However, the clinical pharmacokinetics properties were still far of being ideal and 
BMS-663749 was discarded for further development for the treatment of HIV-1. Therefore, no BMS compound finally progressed on clinical trials.<smiles>COc1ccnc2[nH]cc(C(=O)C(=O)N3CCN(C(=O)c4ccccc4)C[C@H]3C)c12</smiles>

BMS-378806 (14)<smiles>COc1cnc(OC)c2c(C(=O)C(=O)N3CCN(C(=O)c4ccccc4)CC3)c[nH]c12</smiles>

BMS-488043 (15)<smiles>COc1cnc(OC)c2c1c(C(=O)C(=O)N1CCN(C(=O)c3ccccc3)CC1)cn2COP(=O)([O-])O</smiles>

BMS-663749 (16)

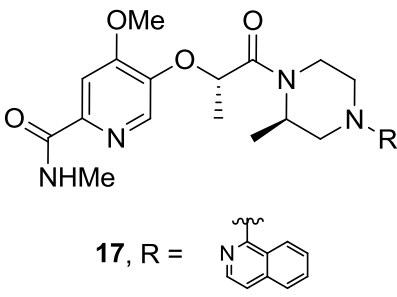<smiles>C[C@H](Oc1cccc2nc(NCCO)ccc12)C(=O)N1CCN(c2nccc3ccccc23)C[C@H]1C</smiles>

Figure 10. Potent CD4 mimics for HIV-inhibition.

The detailed mechanism of inhibition of these compounds remains unclear still and huge debate has arisen around it. It seems nowadays accepted that this family of inhibitors bind to a specific hot-spot domain in the CD4 binding pocket of the viral gp120, attributed to the previously depicted Phe ${ }^{43}$ cavity, preventing its interaction with CD4 [102]. This mechanism could be supported by the fact that BMS378806 induces mutations in gp120 that are located very closely to the CD4-binding pocket [102] [103]. Alternatively, other authors suggested that BMS-378806 really acts in a more subtle way interfering in the gp120-gp41 conformational changes triggered after the attachment to CD4, so as to preclude an efficient rearrangement that finally hampers the entry of the virus [104].

As depicted above, no BMS candidate has made progress in advanced clinical phases. In spite of these discouraging results exposed for the Bristol-Myers Squibb azaindol family, they demonstrated excellent antiviral activity and hence, they constituted a proof-of-concept that establishes the interaction between gp120 and the host receptor CD4 as a viable target and the conserved CD4 binding site in gp120 (Phe ${ }^{43}$ cavity) as a promising hotspot for the design and development of novel small-molecule entry inhibitors.

Simultaneous to the discovery of the BMS-family of gp120-CD4 inhibitors, another potent family was developed by Pfizer laboratories based in the BMS chemotype structure [105]. They focused their attention on the replacement of the chemically and metabolically vulnerable di-ketone group in the 
parent drugs. Compounds 16 and 17 were identified as a result of an exhaustive SAR study which exhibited antiviral activity in the nanomolar range in a wide panel of viral strains and good oral bioavailability in rats (Figure 10) [105a,b]. Although 17 was 10-fold more potent than 18, the predicted human pharmacokinetics for $\mathbf{1 8}$ were superior. It was therefore suggested that $\mathbf{1 8}$ it should be administered in twice daily doses revealing a better potential for HIV-1 treatment, which is nowadays under clinical development. More interesting was the discovery of compound $\mathbf{1 9}$ by the same company that was shown to be very potent in vitro with an $\mathrm{IC}_{50}$ value of $40 \mathrm{pM}$, which has no precedent for the inhibition of the CD4-gp120 attachment so far (Figure 10) [105d]. However, still preclinical and clinical studies are pending for the use of this promising agent in the HIV-1 therapy.

Diverse families of HIV-1 inhibitors have been described sharing the same mechanism of action as BMSs, although exhibiting less potency, whose importance further relies on their novel chemical structure and could constitute good starting points for the development of new generations of structurally diverse gp120-CD4 inhibitors. For instance, in 2009 Botta et al. [106] reported compound 20 using a computational protocol as an anti-HIV-1 agent which was shown to inhibit virus replication in human lymphocyte MT-4 cell cultures at $\mathrm{IC}_{50}$ values of $9 \mu \mathrm{M}$ at subtoxic concentrations (Figure 11). Its particular structure promotes the formation of hydrophobic and hydrogen bond interactions with specific residues in the Phe ${ }^{43}$ cavity; therefore interfering in gp120-CD4 protein-protein interactions. Another example comes from Gilon and co-workers that developed a novel method to convert the non-continuous active regions in CD4 into small macrocyclic molecules with anti-HIV-1 activity [107]. Compound 21 was shown to inhibit HIV-1 infection in the low-micromolar range in vitro and had excellent oral bioavailability and good metabolic stability (Figure 11). Despite these promising properties and its interesting structure, it presented restricted ability to cross biological membranes and further optimization of the pharmacokinetic properties are still needed for further progress.

A different family of agents were identified in 2005 by Debnath et al. [108] using database screening techniques. NBD-566 (22) and NBD-557 (23) were selected as the leading compounds of a chemical library containing a structural common oxalamide core (Figure 11). Molecules 22 and 23 showed micromolar antiviral activity in cell-cell fusion and virus-cell fusion in a variety of cell lines in X4 and R5 tropisms. Surface Plasmon Resonance studies (SPR) and a recent co-crystal structure of gp120-22 confirmed a unique interaction between gp120 and 22 consisting of the projection of the aromatic ring of the NBD chemotype into the Phe ${ }^{43}$ hydrophobic pocket in gp120, therefore, competing with CD4 binding [108] [109]. However, a different mechanistic evolution follows the attachment to the $\mathrm{Phe}^{43}$ cavity. Contrary to the BMS-family, NBD compounds induce subtle conformational changes in gp120 that allows for the premature exposure of the CCR5/CXCR4 binding site. These conformational changes generate a short-lived activated state of the virus that rapidly converts into non-active conformations producing as a result the inhibition of the HIV infection. This intimate novel mechanism of action reached great expectations. However, the limited viral neutralization breadth and moderate antiviral activity exhibited by both NBD compounds precluded further developments but prompted to numerous groups to continue investigations. In this context, first attempts directed to modify the phenyl ring, oxalamide linker and piperidine regions on NBD-556 led to a family of compounds with no 
significant improved potencies. [109b] [110]. A remarkable advance in the NBD family was due to Amos Smith III, who very recently designed a structurally related compound $\mathbf{2 4}$ that showed a substantial improvement in the antiviral and neutralization potency of the parent compound among several viral isolates (Figure 11) [111]. This new compound contains a guanidinium motif replacing the piperidine ring that permitted the establishment of an additional electrostatic interaction between the guanidinium and the residue $\mathrm{Asn}^{368}$ in gp120. Therefore, 24 targets two binding hotspots in gp120 at the same time: the hydrophobic Phe ${ }^{43}$ cavity (common to the NBD chemotype family as previously mentioned) and the new ionic interaction with $\mathrm{Asn}^{368}$. Simultaneously to this paper, Debnath et al. [112] reported compounds NBD-11009 (25) and NBD-11018 (26) that exhibited the best potencies so far for the in vitro inhibition of HIV-1 of the whole NBD structurally-related family $\left(\mathrm{IC}_{50}=1-2 \mu \mathrm{M}\right)$ (Figure 11). As in the previous case, this improvement was due to the creation of multiple interactions between residues in gp120 and the novel NBD agent that strengthen the overall interaction at the binding site. Therefore, as these recent examples clearly state, there is still scope to develop novel small-molecule inhibitors of HIV-1 based in the NBD chemotype.

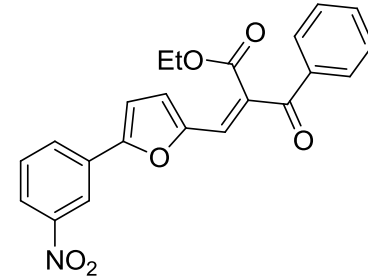

20

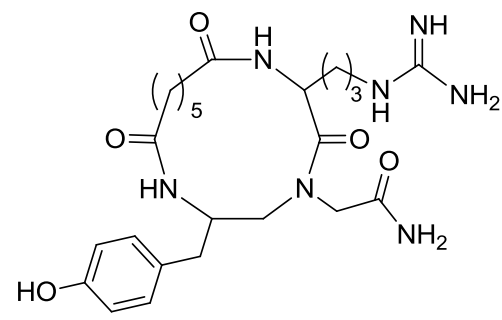

21<smiles>[R]c1ccc(NC(=O)C(=O)NC2CC(C)(C)NC(C)(C)C2)cc1</smiles>

NBD-556 (22), $\mathrm{R}=\mathrm{Cl}$ NBD-557 (23), $\mathrm{R}=\mathrm{Br}$<smiles>N=C(N)N[C@H]1Cc2ccccc2[C@H]1NC(=O)C(=O)Nc1ccc(Cl)c(F)c1</smiles>

24<smiles>[R]Cc1sc(C(NC(=O)C(=O)Nc2ccc(Cl)c(F)c2)C2CCCCN2)nc1C</smiles>

NBD-11009 (25), $\mathrm{R}=\mathrm{OH}$ NBD-11018 (26), $\mathrm{R}=\mathrm{CH}_{2} \mathrm{OH}$

Figure 11. Moderate HIV-1 inhibitors of the CD4-gp120 interaction.

As previously detailed, both compounds NBD-556 (22) and NBD-557 (23) promote conformational changes in gp120 that lead to the exposure of the chemokine co-receptor CCR5/CXCR4 binding sites. In order to obtain NBD-related compounds with better potencies, Tamamura and coworkers designed a strategy based on the conjugation of 22 and other CXCR4 antagonists, reaching hybrid molecules such as $\mathbf{2 7}$ that exhibited enhanced EC $_{50}$ values (nanomolar range) compared to simple CD4 mimics as a result of a significant synergetic effect (Figure 12) [109 a,b]. 


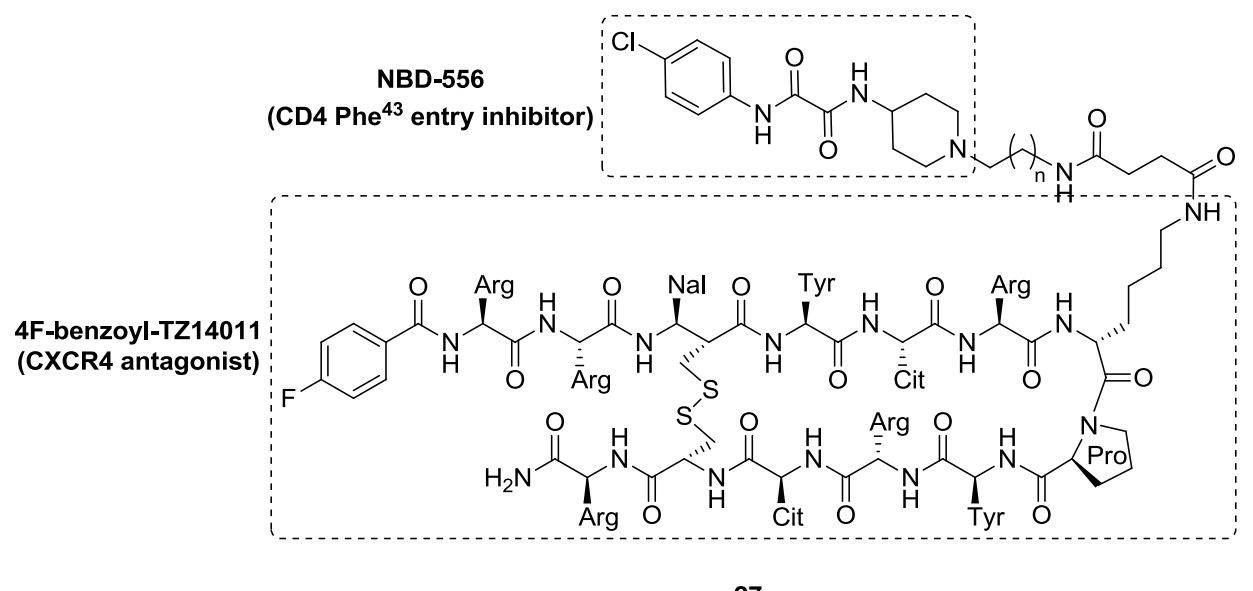

27

Figure 12. Dual inhibitors. NaI = L-3-(2-naphthyl)alanine; Cit = L-citrulline.

This type of strategy that connects two different inhibitors, specifically a CD4 mimic and a chemokine co-receptor antagonist, has been widely used to generate dual HIV-1 inhibitors. The main benefits are: better effectiveness, lower drug dosage and the reduction of the capacity of the virus to develop drug resistances as these agents simultaneously act against complementary therapeutic targets. Chaiken and co-workers recently reported a five-residue peptide $\mathbf{2 8}$ with a central triazol ring that inhibited the binding of gp120 to both CD4 and CCR5/CXCR4 sites and neutralized HIV infection (Figure 13) [113]. Although it exhibited only moderate activity $\left(\mathrm{IC}_{50}=33 \mu \mathrm{M}\right)$ in vitro, the novelty of this compound is related to the central ferrocene ring core, never used before in the design of HIV inhibitors. This is believed to be part of a spatially arranged aromatic cluster that interacts with sterically restricted sites in gp120 while the $N$-terminal extensions of the residues stabilize binding to the protein by additional hydrogen bond interactions. The result is the discovery of a completely novel series of allosteric inhibitors that target small epitopes in gp120, unlike the direct binding to the Phe ${ }^{43}$ cavity in gp120 observed in the previous CD4 mimics that compete for the site of attachment to CD4. Therefore, these developments open a promising window to the development of new inhibitors of gp120 acting through a completely novel mechanism to those described to date.

Better potencies were obtained when dual compounds were obtained by linking a small CD4mimetic peptide to either heparin sulfate (HS) or a sulfated tridecapeptide that mimics HS rendering mCD4-HS ${ }_{12}$ and $\mathrm{mCD} 4-\mathrm{P}_{3} \mathrm{YSO}_{3}$ respectively [114]. These negatively charged compounds have the ability to interact with both the positively charged V3 loop (polyanionic unspecific mechanism) and the proximally located CD4 binding site in gp120, displaying a strong anti-HIV-1 activity in the lownanomolar range in cellular cultures independently of the HIV tropisms. Although they have a relative large molecular mass $(5-6 \mathrm{kDa})$, they are still small in comparison to sCD4/CD4 mimetics nowadays described for the inhibition of HIV-infection. Moreover, the potent and broad antiviral activity confers it a 
great potential to be used in the prevention and treatment of HIV, but further in vivo work and clinical applications are needed.

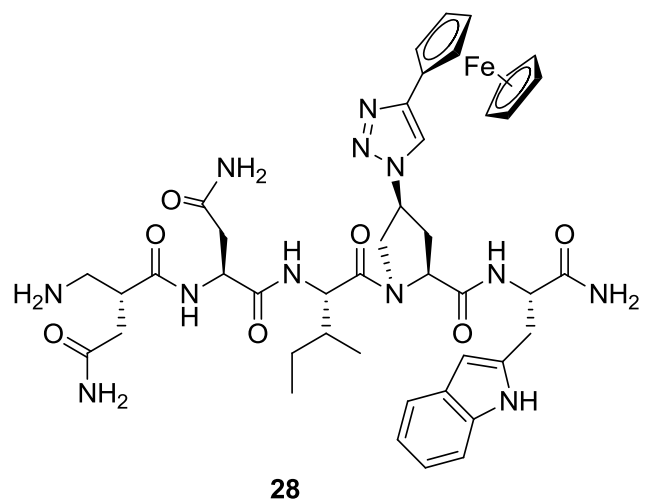

Figure 13. Dual antagonists of HIV-1 gp120.

\subsection{Targeting co-receptor binding sites on gp120}

Another key interaction during the entry process of the HIV-1 into the host cell is between the CD4-gp120 complex mixture and the chemokine co-receptor CCR5 or/and CXCR4. An enormous effort has been devoted to the design and development of agents that inhibit this binding. A proof-of-concept that verifies the success of this strategy is Maraviroc (29, UK-427 857, Selcentry®), which is one of the two entry/fusion inhibitors clinically accepted nowadays for the HIV-1 chemotherapy (Figure 14) [13]. Maraviroc attaches to the CCR5 co-receptor in the target cell blocking the interaction with glycoprotein gp120 and stopping the propagation of the virus in patients. As can be deduced from above, the main effort in the design of inhibitors of the gp120-CCR5/CXCR4 attachment has been directed against the host cell chemokine co-receptor. Thus, only a few compounds targeting the co-receptor binding site in glycoprotein gp120 has been reported. We will focus strictly on the description of the potential inhibitors targeting the co-receptor binding site at gp120 described to date

A series of antibodies (see section 3.5) or high molecular weight molecules directed against this target for HIV-1 inhibition have been proposed. However, they only display a modest neutralizing activity presumably due to the sterically restricted access to the epitope in the virus surface, which avoids a tight interaction. Therefore, there is a demanding interest in small-size molecules able to attach to the chemokine co-receptor binding domain in gp120 for the treatment of the HIV-1 infection. 


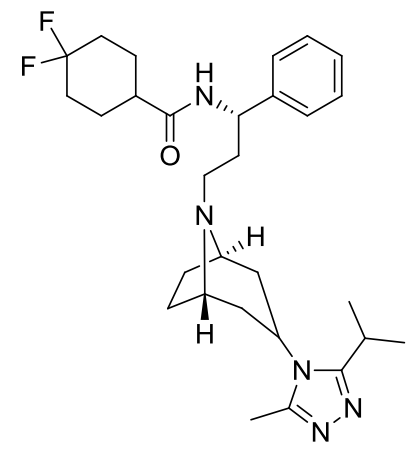

maraviroc (29)

Figure 14. Maraviroc structure.

A representative compound is IC9564 (30), a betulinic acid derivative with substitution at the C28 position that inhibits $\mathrm{A}, \mathrm{B}$, and the most prevalent clade $\mathrm{C} \mathrm{HIV}-1$ viruses at $\mathrm{IC}_{50}$ values as low as 0.07 $\mu \mathrm{M}$ independently of the tropism (Figure 15) [115]. The location of the substituent in $\mathbf{3 0}$ is fundamental for its anti-HIV-1 entry inhibition. It has been hypothesized that C-28 side chain attaches to a conserved region at the base of V3 loop inducing a non-functional gp120 conformation, which is incapable of interacting with the chemokine receptors.

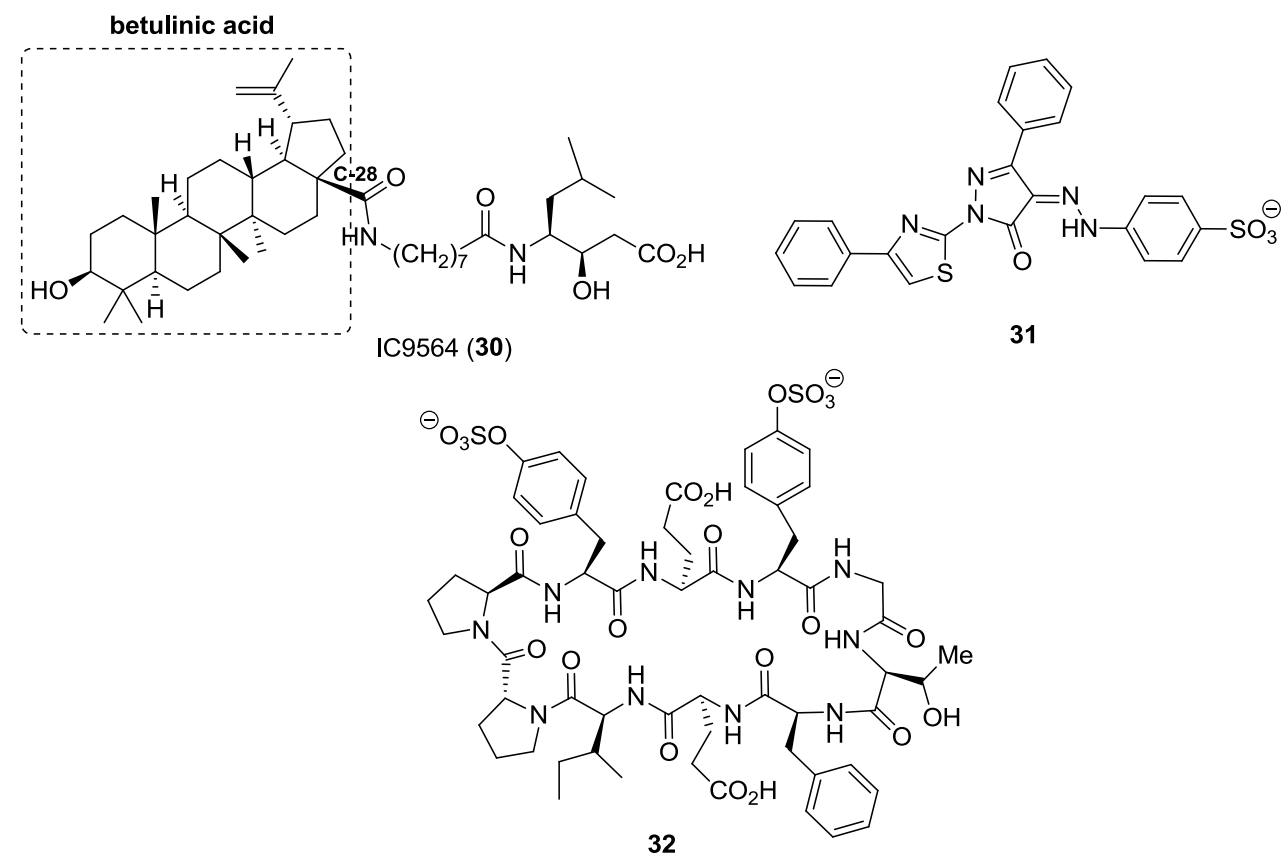

Figure 15. Chemokine co-receptor mimics to inhibit HIV-1 infection. 
A different concept was widely used in recent years for the development of a new family of small-size compounds directed to block the chemokine co-receptor binding site in gp120, such as tyrosine sulfate mimetics. This strategy is based on the interaction of the co-receptor and the CD4-induce (iCD4) epitope in gp120 that requires at least two tyrosine-sulfate (Tys) residues in the extracellular $N$-terminus domain (Nt) of the co-receptor (generally CCR5). Differing from the polyanionic family of gp120inhibitors, these compounds would not establish electrostatic interactions with the target molecule despite the presence in their structures of sulfonyl acid groups. Several authors have focused their attention in developing tyrosine sulfate peptide-like mimetics to inhibit the HIV-1 entry into the host cell. Thus, Bewley and co-workers are pioneers in this area and they have recently identified a novel compound, 31, as a result of an in silico screening (Figure 15). Compound $\mathbf{3 1}$ attaches to CCR5 and CXCR4 type viruses in infected cells inducing both inhibition of HIV-1 entry in the low micromolar range and neutralization by sulfated antibodies that recognize the co-receptor binding site [116]. However, the neutralizing potency of this agent was not effective enough and the authors tried to overcome this problem by using $\mathbf{3 1}$ in combination with other CD4 mimetics. This may imply a previous CD4-gp120 attachment and the exposure of the co-receptor facilitating a neutralizing response. Another example was published in 2010 by Robinson et al. [117] who designed an innovative tyrosine-sulfate peptidomimetic considering the $\alpha$ helical conformation that the Nt-CCR5 adopts when it interacts with the V3 conserved region in gp120. The resulting cyclic structure 32 showed moderate antiviral activity in CCR5 culture cells with no cytotoxicity (Figure 15). NMR and SPR studies permitted the postulation that $\mathbf{3 2}$ assumes a $\beta$-hairpin conformation mimicking the $\alpha$-helical CCR5 epitope and interacts with the V3 conserved region in gp120 with the involvement of the sulfate groups, preventing the attachment of the glycoprotein to the coreceptor.

As stated, the inhibition of HIV entry/fusion process by agents that block the interaction between gp120 and co-receptors is a highly interesting area. In this context, it has been suggested that additional co-factors besides CCR5 and CXCR4 could play an important role, such as membrane glycosphingolipids (GLSs) [118]. The binding of these GLSs to the gp120 protein is believed to be driven by a "stackingtype" interaction established between a Phe residue located in the V3 domain and the hydrophobic face of the galactosyl ring of the glycolipid (presumably $\mathrm{CH}-\pi$ interaction). Blumenthal and co-workers synthesized a family of galactosylceramide derivatives for the HIV-1 treatment and found that compounds LAA-4 (33) and LAA-6 (34) attach to gp120 in a similar way to GLS, inhibiting the cell-tocell fusion and viral entry $\left(\mathrm{IC}_{50}=10-40 \mu \mathrm{M}\right)$ in the absence of any significant cytotoxicity (Figure 16) [119]. The heteroatom at the acetal moiety and the simple side chains seemed to be determinant in both efficacy and solubility, and these agents hold good prospects for further development into potential antiviral agents. 


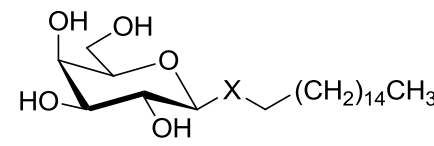

LAA-4 (33), $\mathrm{X}=\mathrm{CH}_{2}$

LAA-6 (34), $X=O$

Figure 16. GLSs co-receptor mimics to inhibit HIV-1 infection.

\subsection{Small-size antibody compounds}

Very few neutralizing antibodies are able to afford effective protection against HIV-1 infection in humans due to the weakly immunogenic and antigenic nature of the envelope protein gp120 (see section 2.1). Numerous studies have been directed towards this concern over the past years and several potent and broadly monoclonal antibodies (mAbs) have been identified to neutralize various primary HIV-1 isolates of different clades in vitro and in simian models in vivo. However, further experiments showed limited potency against non-clade B viruses, which are the majority of the infections outside North America and Europe. In order to solve this limitation, two new neutralizing antibodies, PG9 and PG16, have been recently isolated from African clade-A infected individuals which exhibited anti-HIV activity against clade $\mathrm{B}$ and non-clade $\mathrm{B}$-isolates in vitro $\left(\mathrm{IC}_{50}\right.$ as low as $\left.0.03 \mu \mathrm{M}\right)$ [120].

Despite the promising results obtained for therapies based in neutralizing antibodies, this approach suffers from limitations such as severe side effects, lack of oral bioavailability and high cost. Thus, alternative small-molecules that exploit the powerful properties of antibodies could address many of these disadvantages. Certain solutions have been proposed in this respect such as engineered antibody fragments and antibody-recruiting small molecules. On antibody fragments, two main types can be distinguished: single chain antibody fragments $(\mathrm{scFv})$ and heavy chain variable domain antibodies (dAbs). The success of both families of compounds based on antibody fragments relies on the recognition and establishment of interactions with highly conserved epitopes in gp120 that are inaccessible or only partially accessible during virus entry for larger molecules like full-size antibodies. A representative single chain antibody fragment is $\mathrm{m} 9$, which is active against several panels of primary HIV-1 isolates from clades A-G in cell line-based assays [121]. It showed on average higher potency than the well-known antibodies and the clinically in-use agent efuvirtide. The major neutralizing activity of this compound is exerted after the formation of complex CD4-gp120 via probably the interaction with the binding site of the co-receptor CCR5 in gp120.

An example of a heavy-chain domain antibody is the m36 molecule, the first and unique member of this family of compounds used against HIV-1 therapy [122]. It exhibits exceptional neutralizing activity against diverse HIV-1 strains in culture cells and primary isolates, with potency higher than scFv $\mathrm{m} 9$ generally, but through a different mechanism of action: it is suggested that it targets a highly conserved epitope located close to the CD4 binding site on the gp120-CD4 complex. Despite this, its use as a 
potential vaccine immunogen is limited by a very short half-life circulation in vivo and its sterically restricted epitope.

The second evolving strategy previously mentioned to avoid the problems encountered during the administration of antibodies is the use of antibody-recruiting small molecules (ARM). In 2010 Spiegel et al. [123] presented this novel approach consisting in targeting existing antibodies in the patient and redirecting them to the HIV gp120 envelope glycoprotein. For this purpose, compound $\mathbf{3 5}$ was designed based in the well-known entry inhibitor BMS-378806 (14) that attaches to the CD4 binding site in glycoprotein gp120 (see section 3.3) (Figure 17). They found that $\mathbf{3 5}$ had the ability of both binding to gp120 alone blocking the interaction with CD4 and binding to high-populated anti-dinitrophenyl (antiDNP) antibodies along with protein gp120, forming a ternary complex which increases their visibility to the human immune system. Consequently, a neutralizing enhance response was produced killing either the free virus or infected cells. Compound $\mathbf{3 5}$ demonstrated anti-HIV activity in the micromolar range in ELISA assays and human MT-2 cell cultures and no remarkable cytotoxicity. Therefore, the great potential of this strategy for an effective HIV-1 treatment was proven.

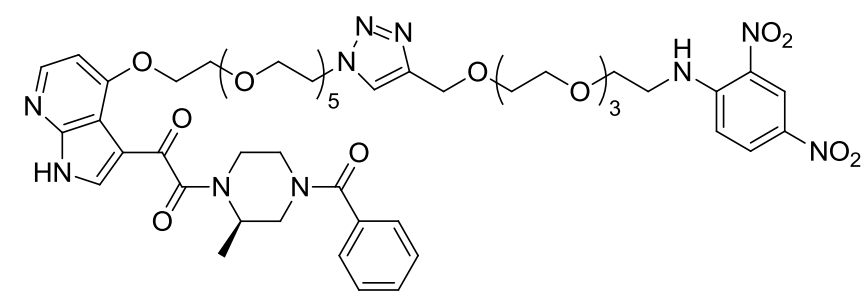

35

Figure 17. Small-size antibody compounds for the HIV-1 therapy.

\subsection{Miscellaneous}

This report has so far provided an overview of the different stages where HIV-1 inhibition can occur during the multi-step entry process by direct binding of the candidate agent to any of the therapeutic targets located in the glycoprotein gp120. However, the inhibition could occur also in an indirect fashion by blocking a molecular target not located in gp120 but ultimately involved in the proper function of the glycoprotein, whose eventual inhibition precludes the HIV-1 entry process. This "indirect inhibition" gained much attention with the discovery of cyclotriazadisulfonamide (CADA, 36) and analogues in the early 2000s, compounds directed to modulate the cellular biosynthesis of CD4 (Figure 18) [124]. This family of inhibitors exhibit broad antiviral activity in the micromolar range in a variety of HIV-1 clinical isolates at no cytotoxic levels. It is believed that these compounds do not directly attach to CD4 but they specifically decrease the CD4 receptor amounts in the surface of lymphocytes without altering the expression of other cellular receptors. Therefore, the inhibition potency shown by $\mathbf{3 6}$ and its derivatives would be directly dependent on the down-regulation expression of the CD4 receptor, thus depriving 
gp120 of its primary receptor at the host cell. Moreover, CADA, formulated as a microbicide gel, demonstrated the preservation of its potency as anti-HIV inhibitor and further studies in non-human primates have been proposed [125].

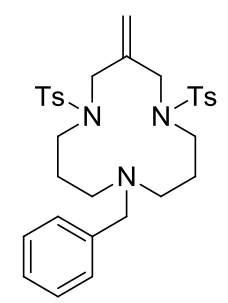

CADA (36)

Figure 18. CADA derivatives as HIV-1 inhibitors.

A different family of "indirect inhibitors" of the HIV-1 entry involving gp120 glycoprotein are the oxidoreductases. These enzymes are located in the cellular surface and are responsible of the formation, reduction and oxidation of disulfide bonds. It has been hypothesized that the HIV-1 entry/fusion process is associated with the reduction of one or more disulfide(s) bond(s) in gp120 that induces conformational changes facilitating the unmasking of the gp41 fusion peptide [126]. Thus, agents that prevent the reduction of these bonds in gp120 would inhibit HIV-1 entry through this novel mechanism in an indirect fashion. There have been three main oxidoreductases described: protein disulfide isomerase (PDI), thioredoxin-1 (Trx1) or glutaredoxin-1. The enzyme that has received the most attention is PDI. Thus, several small-size agents have been described as PDI inhibitors. Among them, Bacitracin (37), the very first agent identified as a PDI inhibitor, and 5,5'-dithiobis-2-nitrobenzoic acid (DTNB, 38) are still of interest nowadays due to their great potential to inhibit HIV-1 (Figure 19) [127]. Besides the attachment to the PDI enzyme to avoid the propagation of the virus from cell-to-cell in CXCR4 tropic cells (in the milimolar range), the interaction of both compounds to the CD4 receptor was also observed. Moreover, $\mathbf{3 8}$ also acts in a late stage of the viral cycle (probably inactivating the protease enzyme) and formulated as a microbicide is able to give cell protection in vitro for hours. Therefore, it is a potential candidate to be used therapeutically in HIV-1 patients and advanced trials have to be performed to evaluate their toxicity and side effects.

There are currently more novel compounds under investigation to block the reductase PDI function. In 2011, Osada group identified a family of Juniferdin derivatives 39 as new potential PDI inhibitors using high-throughput screening (Figure 18) [128]. These compounds specifically inhibit the PDI-catalyzed reduction function in the cell surface and block the HIV-entry in several cultured cells lines with $\mathrm{IC}_{50}$ values of approximately $160 \mathrm{nM}$. More importantly, Juniferdin derivatives are less cytotoxic than the PDI-inhibitors described to date, confirming that further in vivo studies should be performed to assess their potential clinical development. 
More efforts have been devoted to find inhibitors of thioredoxin-1 (Trx1), which is the enzyme with the strongest reducing activity of the three oxidoreductases located extracellularly. A recent study made by Reiser at al. [129] has to be highlighted. In this work, a novel indirect strategy was used to find a Trx1 inhibitor based on targeting the redox system that supplies electrons to the enzyme and drives forward the redox process. Thus, an organo-gold compound, Auranofin (40), was demonstrated to efficiently decrease viral loads and increase T-cell counts in patients by the inhibition of the reduction of gp120. Unfortunately, this effect is carried out by $\mathbf{4 0}$ close to its cytotoxic concentrations (Figure 18). It was postulated that inhibition of thioredoxin reductase (the electron donor of Trx1 and PDI), could restrict the reducing activity of both enzymes. Additionally, it has been also established that some CBPs, previously shown to bind to carbohydrates of gp120 (see section 3.2.1), inhibit the action of Trx1 and PDI, presumably by sterically hindering the access of the enzymes to the virus surface. However, high quantities of the compounds were required and low activities were observed.

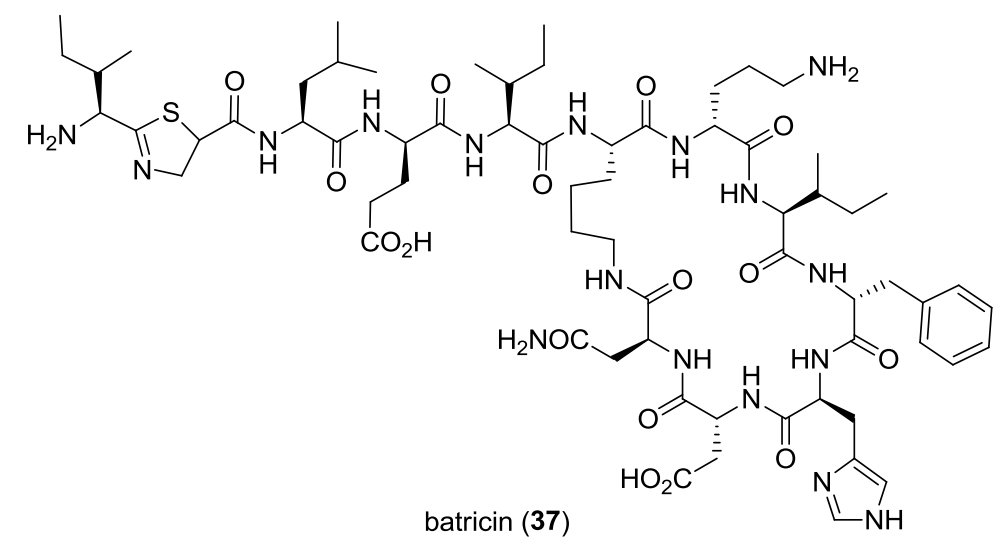<smiles>O=C(O)c1cc(SSc2ccc([N+](=O)[O-])c(C(=O)O)c2)ccc1[N+](=O)[O-]</smiles>

DTNB (38)

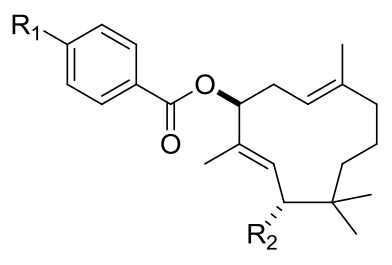

juniferdin derivatives (39)

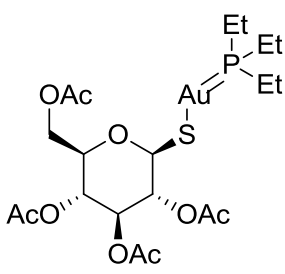

auranofin (40)

Figure 19. HIV-1 inhibitors that block the oxidoreductase activity in the gp120 surface.

As outlined above, the redox regulation of the gp120 glycoprotein could be an important indirect strategy for anti-HIV therapy and nowadays, the development of novel compounds that specifically interfere in the reduction of gp120 disulfides is of great interest. 


\section{Conclusions}

The fight against AIDS is entering a decisive period. While the development of an effective vaccine remains still far away, the treatment of the disease has been entrusted to the currently available chemotherapeutic arsenal. Barely 30 years after the discovery of HIV as the etiological cause of AIDS, the disease has been converted into a chronic controlled infection. Despite this major achievement, we have to display nevertheless only a moderate optimism, because while HAART regiments have decisively contributed to control the development of the HIV infection until suppression of pathological expressions of AIDS, drug resistances, toxicities and side-effects are still important drawbacks that compromise a definitive effective treatment. Moreover, latent long-term reservoirs of the pathogen are a major hurdle for the complete suppression of HIV from the organism.

For the reasons depicted above, the discovery and development of novel chemotherapeutics directed against new targets in the HIV replicative cycle are still required for the treatment of HIV infection. These novel drugs should be used in combination with conventional retrovirals in HAART in order to inhibit HIV at as many levels as possible and minimize the risk of resistances. In this context, HIV entry was put in the spotlight as a critical process susceptible of effective inhibition. Viral entry inhibition additionally has the advantage of blocking the progress of the infection at the early steps, preserving an uninfected population of target cells.

Glycoprotein gp120 is one of the molecular structures involved in the viral machinery leading entry of HIV into the host cell, playing a preeminent role in the mediation of CD4 receptor attachment as well as co-receptor binding, triggering the complex process that eventually delivers the viral material inside the host cell. This protein has emerged as a promising target for the development of HIV inhibitors as the knowledge on its role in the entry process as well as detailed structural and intimate mechanistic information have increased. As can be concluded from this overview, gp120 offers a wide set of different possibilities to interfere with its normal function. From unspecific electrostatic interactions established between negatively charged molecules (polyanions) and positively charged domains of the protein, to selective binding to sugar residues of the gp120 glycans (CBAs), both precluding efficient attachment, passing through protein-protein interaction inhibition such as CD4 or co-receptor binding, every family of gp120 inhibitors has a unique profile from the structural and mechanistic point of view. The great therapeutic relevance of gp120 inhibition has encouraged the search for molecular structures endowed with a higher inhibitory potency and selectivity towards this protein, producing a heterogeneous array of drugs that act at multiple points of the gp120 structure and are contributing positively to the increase of the potential therapeutic arsenal against HIV. Moreover, some strategies described, such as the CBA approach, have a great conceptual originality.

Although there is no gp120 inhibitors clinically approved to date, many drug candidates have exhibited remarkable activities and some of them have been evaluated in preclinical or clinical trials with promising profiles to be used in the HIV-1 therapy. Additionally, gp120 inhibitors could also prevent viral transmission, opening a promising window to their use as microbicides. Definitively, gp120 is a 
challenging target for HIV chemotherapy. Due to their great potential and novelty, research on drugs directed to inhibit gp120 should be emphasized and exploited in the future. Glycoprotein gp120 is thus at the forefront of strategies to treat and prevent HIV infection.

\section{Acknowledgements}

This work was supported by the Spanish MICINN (project SAF2009-13914-C02-01). A. Flores acknowledges financial support from a contract JAE-Doc (Programa Junta para la Ampliación de Estudios) co-funded by CSIC and UE (FSE, Fondo Social Europeo). Dr. Eva María Priego is acknowledged for her assistant in the edition of the gp120 structures (Figure 1). Dr. Maria Nash is acknowledged for a critical reading and her valuable comments on this article.

\section{References}

[1] UNAIDS report on the global AIDS epidemic 2012. Published November 20, 2012. http://www.unaids.org/en/media/unaids/contentassets/documents/epidemiology/2012/gr2012/20121 120_UNAIDS_Global_Report_2012_en.pdf (accessed November 28, 2012).

[2] (a) Pitisuttithum, P.; Rerks-Ngarm, S.; Bussaratid, V.; Dhitavat, J.; Maekanantawat, W.; Pungpak, S.; Suntharasamai, P.; Vanijanonta, S.; Nitayapan, S.; Kaewkungwal, J.; Benenson, M.; Morgan, P.; O'Connell, R.J.; Berenberg, J.; Gurunathan, S.; Francis, D.P.; Paris, R.; Chiu, J.; Stablein, D.; Michael, N.L.; Excler, J.-L.; Robb, M.L.; Kim, J.H. Safety and Reactogenicity of Canarypox ALVAC-HIV (vCP1521) and HIV-1 gp120 AIDSVAX B/E Vaccination in an Efficacy Trial in Thailand. PLoS ONE, 2011, 6 (12), e27837. (b) García, F.; Climent, N.; Assoumou, L.; Gil, C.; González, N.; Alcamí, J.; León, A.; Romeu, J.; Dalmau, J.; Martínez-Picado, J.; Lifson, J.; Autran, B.; Costagliola, D.; Clotet, B.; Gatell, J.M.; Plana, M.; Gallart, T. A Therapeutic Dendritic CellBased Vaccine for HIV-1 Infection. J. Infect. Dis., 2011, 203, 473-478.

[3] (a) Gibson R.M.; Arts E.J. Past, present, and future of entry inhibitors as HIV microbicides, Curr HIV Res., 2012, 10(1), 19-26. (b) Kelly, C.G., Shattock, R.J. Specific microbicides in the prevention of HIV infection,. J. Intern. Med., 2011, 270(6), 509-519. (c) Pozzetto, B.; Delézay, O.; BrunonGagneux, A.; Hamzeh-Cognasse, H.; Lucht, F.; Bourlet, T. Current and future microbicide approaches aimed at preventing HIV infection in women. Expert Rev. Anti. Infect. Ther., 2012, 10(2), 167-183. (d) Cutler, B.; Justman, J. Vaginal microbicides and the prevention of HIV transmission. Lancet Infect. Dis., 2008, 8(11), 685-697.

[4] (a) An up-to-date list of approved drugs against HIV infections is available at http://www.fda.gov (accessed August 6, 2012) (b) De Clercq, E. Anti-HIV drugs: 25 compounds approved within 25 years after the discovery of HIV. Int. J. Antimicrob. Agents, 2009, 33, 307-320. (c) Perno, C.F.; 
Svicher, V.; Shols, D.; Pollicita, M.; Balzarini, J.; Aquaro, S. Therapeutic strategies towards HIV-1 infection in macrophages. Antivir. Res., 2006, 71, 293-300.

[5] Pomerantz, R.J.; Horn, D.L. Twenty years of therapy for HIV 1 infection. Nat. Med., 2003, 9, 867873.

[6] (a) Yeni, P.G.; Hammer, S.M.; Hirsch, M.S.; Saag, M.S.; Schechter, M.; Carpenter, C.C.J.; Fischl, M.A.; Gatell, J.M.; Gazzard, B.G.; Jacobsen, D.M.; Katzenstein, D.A.; Montaner, J.S.G.; Richman, D.D.; Schooley, R.T.; Thompson, M.A.; Vella, S.; Volberding, P.A. Treatment for adult HIV infection. 2004 recommendations of the International AIDS Society-USA panel. J. Am. Med. Assoc., 2004, 292, 251-265; (b) Butera, S.T. HIV Chemotherapy: A Critical Review, $1^{\text {st }}$ ed.; Caister Academic Press: Norwich, 2005.

[7] (a) Deeks, S.G.; Autran, D.; Berkhout, B.; Benkirane, M.; Cairns, S.; Chomont, N.; Chun, T.-W.; Churchill, M.; Di Mascio, M.; Katlama, C.; Lafeuillade, A.; Landay, A.; Lederman, M.; Lewin, S. R.; Maldarelli, F.; Margolis, D.; Markowitz, M.; Martinez-Picado, J.; Mullins, J.I.; Mellors, J.; Moreno, S.; O'Doherty, U.; Palmer, S.; Penicaud, M.-C.; Peterlin, M.; Poli, G.; Routy, J.P.; Rouzioux, C.; Silvestri, G.; Stevenson, M.; Telenti, A.; Van Lint, C.; Verdin, E.; Woolfrey, A.; Zaia, J.; Barré-Sinoussi, F. Towards an HIV cure: a global scientific strategy. Nature Rev. Immunol., 2012, 12, 607-614. (b) Lefeuillade, A. Eliminating the HIV reservoir. Curr. HIV/AIDS reports, 2012, 9(2), 121-131. (c) Coiras, M.; López-Huertas, M.R.; Pérez-Olmeda, M.; Alcamí, J. Understanding HIV-1 latency provides clues for the eradication of long-term reservoirs. Nat. Rev. Microbiol., 2009, 7, 798-812. (d) Shen, L.; Siliciano, R.F. Viral reservoirs, residual viremia, and the potential of highly active antiretroviral therapy to eradicate HIV infection. J. Allergy Clin. Immun., 2008, 122, 22-28; (e) Pomerantz, R.J. Reservoirs of human immunodeficiency virus type 1: The main obstacles to viral eradication. Clin. Infect. Dis., 2002, 34, 91-97; (f) Pierson, T.; McArthur, J.; Siciliano, R. J. Reservoir for HIV-1: mechanism for viral persistence in the presence of antiviral immune response and antiretroviral therapy. Annu. Rev. Immunol., 2000, 18, 665-708. (g) Chun, TW.; Fauci, A.S. Latent reservoirs of HIV: obstacles to the eradication of virus. Proc. Natl. Acad. Sci. USA, 1999, 96(29), 10958-10961.

[8] Hawkins, T. Understanding and managing the adverse effects of antiretroviral therapy. Antiviral Res., 2010, 85(1), 201-209.

[9] (a) Lucas, G.M.; Chaisson, R.E.; Moore, R.D. Highly active antiretroviral therapy in a large urban clinic: risk factors for virologic failure and adverse drug reactions. Ann. Intern. Med., 1999, 131, 8187. (b) Yerly, S.; Kaiser, L.; Race, E.; Bru, J.P.; Clavel, F.; Perrin, L. Transmission of antiretroviraldrug-resistant HIV-1 variants. The Lancet, 1999, 354, 729-733.

[10] Perno, C.F.; Moyle, G.; Tsoukas, C.; Ratanasuwan, W.; Gatell, J.; Schechter, M. Overcoming resistance to existing therapies in HIV-infected patients: the role of new antiretroviral drugs. J. Med. Virol., 2008, 80, 565-576. 
[11] Robertson, D. US FDA approves new class of HIV therapeutics. Nat. Biotechnol., 2003, 21, 470471.

[12] Dorr, P.; Westby, M.; Dobbs, S.; Griffin, P.; Irvine, B.; Macartney, M.; Mori, J.; Rickett, G.; SmithBurchnell,C.; Napier, C.; Webster, R.; Armour, D.; Price, D.; Stammen, B.; Wood, A.; Perros, M. Maraviroc (UK-427,857), a potent, orally bioavailable, and selective small-molecule inhibitor of chemokine receptor CCR5 with broad-spectrum anti-human immunodeficiency virus type 1 activity. Antimicrob. Agents Chemother., 2005, 49, 4721-4732.

[13] (a) Lorenzen, T.; Stoehr, A.; Walther, I.; Plettenberg, A. CCR5 antagonist in the treatment of treatment-experienced patients infected with CCR5 tropic HIV-1. Eur. J. Med. Res., 2007, 12, 419425; (b) Lalezari, J.; Henry, K.; O’Hearn, M.; Montaner, J.S.G.; Piliero, P.J.; Trottler, B.; Walmsley, S.; Cohen, C.; Kuritzkes, D.R.; Eron, J.J.; Chung, J.; DeMasl, R.; Donatacci, L.; Drobnes, C.; Delehanty, J.; Salgo, M.; Farthing, C.; Graham, E.; Packard, M.; Ngo, L.; Lederman, M.; Baum, J.; Pollard, R.; Rauf, S.; Silkowski, W.; Thompson, M.; Rucker, A.; Harris, M.; Larsen, G.; Preston, S.; Cunningham, D.; Guimaraes, D.; Bertasso, A.; Kinchelow, T.; Myers, R.; Casimir, B.; Skolnik, P. R.; Adams, B.; Leite, O.H.M.; Oliveira, M.; Lefebvre, E.; Gomez, B.; Foy, K. B.; Lampiris, H.; Charles, S.; Dobkin, J.; Crawford, M.; Slom, T.; Murphy, R.; Mikaitis, T.; Witek, J.; Anthony, R.; Richmond, G.; Appleby, V.F.; Smaill, F.; Kelleher, L.; Nieto, L.; Trevino, S.; Schechter, M.; Fonseca, B.; DeJesus, E.; Ortiz, R.; Wheat, J.; Goldman, M.; O'Connor, D. K.; Sierra-Madero, J.G.; Nino-Oberto, S.; Gallant, J. E.; Apuzzo, L.; Bosgoz, N.; Habeeb, K.; Alpert, P.; Thomas, S.; Miller, T.; Kempner, T.; Wolfe, P.R.; Bautista, J.; Martin, H.L.; Morton, M.E.; Henry, D.; Kilcoyne, S.; Glutzer, E.; Rivera-Vazquez, C.; Pomales, Z.; Bellos, N.; Hoffman, L.A.; Olmscheid, B.; Klein, O.; Miller, M.; Steinhart, C.R.; Liebmann, A.; Williams, S.; Springate, L.; Logue, K.; Smiley, L.; Miralles, G.D.; Haubrich, R.; Nuffer, K.; Beatty, G.; O'Leary, S.; Rouleau, D.; Dufresne, S.; Kilby, J.M.; Saag, M.; Upton, K.; Feinberg, J.; Kohler, P.; Campbell, T.B.; Putnam, B.A.; Riddler, S.A.; Rosener, R.R.; Barnett, B.J.; Hansen, I.; Collier, A.C.; Royer, B.A.; Haas, D.W.; Morgan, M.; Sathasivam, K.; Hersch, J. Enfuvirtide, an HIV-1 fusion inhibitor, for drug-resistant HIV infection in North and South America. N. Engl. J. Med., 2003, 348, 2175-2185.

[14] For recent reviews of entry HIV-1 inhibitors see: (a) Hertje, M.; Zhou, M.; Dietrich, U. Inhibition of HIV-1 entry: multiple keys to close the door. ChemMedChem., 2010, 11, 1825-1835. (b) Teixeira, C.; Gomes, J.R.B.; Gomes, P.; Maurel, F. Viral surface glycoproteins, gp120 and gp41, as potential drug targets against HIV-1: brief overview one quarter of a century past the approval of zidovudine, the first anti-retroviral drug. Eur. J. Med. Chem., 2011, 46, 979-992. (c) Didigu, C.A.; Doms, R.W. Novel approaches to inhibit HIV entry. Viruses 2012, 4, 309-324. (d) Qian, K.; Morris-Natschke, S. L.; Lee, K.H. HIV entry inhibitors and their potential in HIV therapy. Med. Res. Rev., 2009, 29, 369393. (e) Saha, L. HIV entry inhibitors: current status. J. Clin. Diagn. Res., 2008, 2, 1119-1125.

[15] (a) Liu, S.; Chen, Z.; Wang, Y. Human immunodeficiency virus entry inhibitors targeting HIV-1 gp120: research advances. Guoji Yaoxue Yanjiu Zazhi, 2011, 38, 89-95. (b) Kadow, J.; Wang, H.- 
G.H.; Lin, P.-F. Small-molecule HIV-1 gp120 inhibitors to prevent HIV- entry: An emerging opportunity for drug development. Curr. Opin. Investig. Drugs, 2006, 7(8), 721-726.

[16] (a) Kwong, P.D.; Wyatt, R.; Robinson, J.; Sweet, R.W.; Sodroski, J.; Hendrickson, W.A. Structure of an HIV gp120 envelope glycoprotein in complex with the CD4 receptor and a neutralizing human antibody. Nature, 1998, 393, 648-659. (b) Kwong, P.D.; Wyatt, R.; Majeed, S.; Robinson, J.; Sweet, R. W.; Sodroski, J.; Hendrickson W. A. Structures of HIV-1 gp120 envelope glycoproteins from laboratory-adapted and primary isolates. Structure, 2000, 8, 1329-1339. (c) Huang C.C.; Tang, M.; Zhang, M.-W.; Majeed, S.; Montabana, E.; Stanfield, R.L.; Dimitrov, D.S.; Korber, B.; Sodroski, J.; Wilson, I.A.; Wyatt, R.; Kwong, P.D. Structure of a V3-containing HIV-1 gp120 core. Science, 2005, 310, 1025-1028. (d) Huang, C.C.; Lam, S.N.; Acharya, P.; Tang, M.; Xiang, S.H.; Hussan, S.S.; Stanfield, R.L.; Robinson, J.; Sodroski, J.; Wilson, I.A.; Wyatt, R.; Bewley, C.A.; Kwong, P.D. Structures of the CCR5 N terminus and of a tyrosine-sulfated antibody with HIV-1 gp120 and CD4. Science, 2007, 317, 1930-1934. (e) Pancera, M.; Majeed, S.; Ban, Y.E.; Chen, L.; Huang, C.C.; Kong, L.; Kwon, Y.D.; Stuckey, J.; Zhou, T.; Robinson, J.E.; Schief, W.R.; Sodroski, J.; Wyatt, R.; Kwong, P.D. Structure of HIV-1 gp120 with gp41-interactive region reveals layered envelope architecture and basis of conformational mobility. Proc. Natl. Acad. Sci. USA, 2010, 107, 11661171. (f) Chen, B.; Vogan, E.M.; Gong, H.; Skehel, J.J.; Wiley, D.C.; Harrison, S.C. Structure of an unliganded simian immunodeficiency virus gp120 core. Nature, 2005, 433, 834-841. (g) Diskin, R.; Marcovecchino, P.M.; Bjorkman, P.J. Structure of a clade C HIV gp120 plus CD4 and a CD4induced antibody reveals anti-CD4 polyreactivity. Nat. Struct. Mol. Biol., 2010, 17, 608. (h) Zhou T.; Xu, L.; Dey, B.; Hessell, A.J.; Van Ryk, D.; Xiang, S.-H.; Yang, X.; Zhang, M.-Y.; Zwick, M.B.; Arthos, J.; Burton, D.R.; Dimitrov, D.S.; Sodroski, J.; Wyatt, R.; Nabel, G.J.; Kwong, P.D. Structural definition of a conserved neutralization epitope on HIV-1 gp120. Nature, 2007, 445, 732737. (i) Chen, L.; Kwon, Y.D.; Zhou, T.; Wu, X.; O’Dell, S.; Cavacini, L.; Hessell, A.J.; Pancera, M.; Tang, M.; Xu, L.; Yang, Z.-Y.; Zhang, M.-Y.; Arthos, J.; Burton, D.R.; Dimitrov, D.S.; Nabel, D.J.; Posner, M.R.; Sodroski, J.; Wyatt, R.; Mascola J.R.; Kwong, P.D. Structural basis of immune evasion at the site of CD4 attachment on HIV-1 gp120. Science, 2009, 326,1123-1127. (j) Zhou, T.; Georgiev, I.; Wu, X.; Yang, Z.-Y.; Dai, K.; Finzi, A.; Kwon, Y.D.; Scheid, J.F.; Shi, W.; Xu, L.; Yang, Y.; Zhu, J.; Nussenzweig, M.C.; Sodroski, J.; Shapiro, L.; Nabel, G.J.; Mascola, J.R.; Kwong, P.D. Structural basis for broad and potent neutralization of HIV-1 by antibody VRC01. Science, 2010, 329, 811-817. (k) Moebius, U.; Clayton, L.K.; Abraham, S.; Harrison II, S.C.; Reinherz, E.L. The human immunodeficiency virus gp120 binding site on CD4: delineation by quantitative equilibrium and kinetic binding studies of mutants in conjunction with a high-resolution CD4 atomic structure. J. Exp. Med., 1992, 176, 507-517.

[17] Kwon, Y.D.; Finzi, A.; Wua, X.; Dogo-Isonagie, C.; Lee, L.K.; Moore, L.R.; Schmidt, S.D.; Stuckey, J.; Yang, Y.; Zhou, T.; Zhua, J.; Vicic, D.A.; Debnath, A.K.; Shapiro, L.; Bewley, C.A.; Mascola, J.R.; Sodroski, J.G.; Kwong P.D. Unliganded HIV-1 gp120 core structures assume the CD4-bound conformation with regulation by quaternary interactions and variable loops. Proc. Natl. Acad. Sci. USA, 2012, 109(15), 5663-5668. 
[18] Leonard, C.K.; Spellman, M.W.; Riddle, L.; Harris, R.J.; Thomas, J.N.; Gregory, T.J. Assignment of intrachain disulfide bonds and characterization of potential glycosylation sites of the type 1 recombinant human immunodeficiency virus envelope glycoprotein (gp120) expressed in Chinese hamster ovary cells. J. Biol. Chem., 1990, 265, 10373-10382.

[19] Pantophlet, R.; Burton D.R., gp120: target for neutralizing HIV-1 antibodies, Annu. Rev. Immunol. 2006, 24, 739-769.

[20] Sato, S.; Ouellet, M.; St-Pierre, C.; Tremblay, M.J. Glycans, galectins, and HIV-1 infection. Ann. N, Y. Acad. Sci., 2012, 1253, 133-148.

[21] (a) Bonomelli, C., Doores, K.J.; Dunlop, D.C.; Thaney, V.; Dwek, R. A.; Burton, D.R.; Crispin, M.; Scanlan, C.N. The glycan shield of HIV is predominantly oligomannose independently of production system or viral clade. PLoS One, 2011, 6, e23521; (b) Doores, K.J., Bonomelli, C.; Harvey, D.J.; Vsiljevic, S. Envelope glycans of immunodeficiency virions are almost entirely oligomannose antigens. Proc. Natl. Acad. Sci. USA, 2010, 170, 13800-13805.

[22] Weis, W.I.; Taylor, M.E.; Drickamer, K. The C-type lectin superfamily in the immune system. Immunol. Rev., 1998, 163, 19-34.

[23] Wyatt, R.; Kwong, P.D.; Desjardins, E.; Sweet, R.G.; Robinson, J.; Hendrickson, W.A.; Sodroski, J.G. The antigenic structure of the HIV gp120 envelope glycoprotein. Nature, 1998, 393, 705-711.

[24] (a) Wei, X.; Decker, J.M.; Wang, S.; Hui, H.; Kappes, J.C.; Wu, X.; Salazar-Gonzalez, J.F.; Salazar, M.G.; Kilby, J.M.; Saag, M.S.; Komarova, N.L.; Nowak, M.A.; Hahn, B.H.; Kwong, P.D.; Shaw, G.M. Antibody neutralization and escape by HIV-1. Nature, 2003, 422, 307-312. (b) Reitter, J.N.; Means, R.E.; Desroiers, R.C. A role for carbohydrates in immune evasion in AIDS. Nat. Med., 1998, 4, 679-684.

[25] (a) Pöhlmann, S.; Baribaud, F.; Lee, B.; Leslie, G.J.; Sánchez, M.D.; Hiebenthal-Millow, K.; Münch, J.; Kirchhoff, F.; Doms, R.W. DC-SIGN Interactions with Human Immunodeficiency Virus Type 1 and 2 and Simian Immunodeficiency Virus J. Virol., 2001, 75, 4664-4672. (b) Cunningham, A.L.; Harman, A.N.; Donaghy H. DC-SIGN 'AIDS' HIV immune evasion and infection. Nat. Immunol., 2007, 8, 556-558.

[26] (a) Lev, N.; Fridmann-Sirkis, Y.; Blank, L.; Bitler, A.; Epand, R.F.; Epand, R.M.; Shai, Y. Conformational Stability and Membrane Interaction of the Full-Length Ectodomain of HIV-1 gp41: Implication for Mode of Action. Biochemistry, 2009, 48, 3166-3175. (b) Zwick, M.B.; Saphire, E.O.; Burton, D.R. gp41: HIV's shy protein. Nature Medicine, 2004, 10, 133-134.

[27] (a) Weissenhorn, W.; Dessen, A.; Harrison, S.C.; Skehel, J.J.; Wiley, D.C. Atomic structure of the ectodomain from HIV-1 gp41. Nature, 1997, 387, 426-430. (b) Buzon, V.; Natrajan, G.; Schibli, D.; Campelo, F.; Kozlov, M.M.; Weissenhorn, W. Crystal structure of HIV-1 gp41 including both fusion peptide and membrane proximal external regions. PLoS Pathog., 2010, 6(5), e1000880. 
[28] (a) Chan, D.C.; Kim, P.S. HIV entry and its inhibition. Cell, 1998, 93, 681-684 (b) Klasse, P.J. The molecular basis of HIV entry. Cell. microbiol., 2012, 14(8), 1183-1192.

[29] For reviews on polyanionic inhibitors of HIV see: (a) Baranova, E.O.; Shastina, N.S.; Shvets, V.I. Polyanionic Inhibitors of HIV Adsorption. Russ. J. Bioorg. Chem., 2011, 37, 527-542. (b) Dhawan, D.; Mayer, K.H. Microbicides to prevent HIV transmission: overcoming obstacles to chemical barrier protection. J. Infect. Dis., 2006, 193, 36-44. (c) Pirrone, V.; Wigdahl, B.; Krebs, F.C. The rise and fall of polyanionic inhibitors of the human immunodeficiency virus type 1. Antivir. Res., 2011, 90, 168-182.

[30] (a) Neurath, A.R.; Strick, N.; Li, Y.-Y. Role of seminal plasma in the anti-HIV-1 activity of candidate microbicides. BMC Infect. Dis., 2006, 6, 150; (b) Shattock, R.J.; Moore, J.P. Inhibiting sexual transmission of HIV-1 infection. Nat. Rev. Microbiol., 2003, 1, 25-34.

[31] Turville, S.G.; Aravantinou, M.; Miller, T.; Kenney, J.; Teitelbaum, A.; Hu, L.; Chudolij, A.; Zydowsky, T.M.; Piatak, M., Jr.; Bess, J. W., Jr.; Lifson, J.D.; Blanchard, J.; Gettie, A.; Robbiani, M. Efficacy of carraguard-based microbicides in vivo despite variable in vitro activity. PLoS One, 2008, 3, e3162.

[32] (a) Sachdev, D.D.; Zerhouni-Layachi, B.; Ortigoza, M.; Profy, A.T.; Tuen, M.; Hioe, C.E.; Klotman, M.E. The differential binding and activity of PRO 2000 against diverse HIV-1 envelopes. J. Acquir. Immune Defic. Syndr., 2009, 51, 125-129; (b) Rusconi, S.; Moonis, M.; Merrill, D.P.; Pallai, P.V.; Neidhardt, E.A.; Singh, S.K.; Willis, K.J.; Osburne, M.S.; Profy, A.T.; Jenson, J.C.; Hirsch, M.S. Naphthalene sulfonate polymers with CD4-blocking and anti-human immunodeficiency virus type 1 activities. Antimicrob. Agents Chemother., 1996, 40, 234-236.

[33] (a). Schwartz, J.L,; Mauck, C.; Lai, J.J.; Creinin, M.D.; Brache, V.; Ballagh, S.A.; Weiner, D.H.; Hillier, S.L.; Fichorova, R.N.; Callahan, M. Fourteen-day safety and acceptability study of $6 \%$ cellulose sulfate gel: a randomized double-blind Phase I safety study. Contraception, 2006, 74, 133140; (b) Jespers, V.; Buve, A.; Van Damme, L. Safety trial of the vaginal microbicide cellulose sulfate gel in HIV-positive men. Sex. Transm. Dis., 2007, 34, 519-522.

[34] Coggins, C.; Blanchard, K.; Alvarez, F.; Brache, V.; Weisberg, E.; Kilmarx, P.H.; Lacarra, M.; Massai, R.; Mishell, D., Jr.; Salvatierra, A.; Witwatwongwana, P.; Elias, C.; Ellertson, C. Preliminary safety and acceptability of a carrageenan gel for possible use as a vaginal microbicide. Sex. Transm. Infect., 2000, 76, 480-483.

[35] Karim, S.S.A.; Richardson, B.A.; Ramjee, G.; Hoffman, I.F.; Chirenje, Z.M.; Taha, T.; Kapina, M.; Maslankowski, L.; Coletti, A.; Profy, A.; Moench, T.R.; Piwowar-Manning, E.; Mâsse, B.; Hillier, S. L.; Soto-Torres, L. Safety and effectiveness of BufferGel and 0.5\% PRO 2000 gel for the prevention of HIV infection in women. AIDS, 2011, 25, 957-966.

[36] Van Damme, L.; Govinden, R.; Mirembe, F.M.; Guédou, F.; Solomon, S.; Becker, M.L.; Pradeep, B.S.; Krishnan A.K.; Alary, M.; Pande, B.; Ramjee, G.; Deese, J.; Crucitti, T.; Taylor, D. Lack of 
effectiveness of cellulose sulfate gel for the prevention of vaginal HIV transmission. New Engl. J. Med., 2008, 359, 463-472.

[37] Skoler-Karpoff, S.; Ramjee, G.; Ahmed, K.; Plagianos, M.G.; Friedland, B.; Govender, S.; De Kock, A.; Cassim, N.; Palanee, T.; Dozier, G.; Maguire, R.; Lahteenmaki, P. Efficacy of Carraguard for the prevention of HIV infection in women in South Africa: a randomized, double-blind placebocontrolled trial. The Lancet, 2008, 372, 1977-1987.

[38] McCormack, S.; Ramjee, G.; Kamali, A.; Rees, H.; Crook, A.M.; Gafos, M.; Jentsch, U.; Pool, R.; Chisembele, M.; Kapiga, S.; Mutemwa, R.; Vallely, A.; Palanee, T.; Sookrajh, Y.; Lacey, C. J.; Darbyshire, J.; Grosskurth, H.; Profy, A.; Nunn, A.; Hayes, R.; Weber, J. PRO 2000 vaginal gel for prevention of HIV-1 infection (Microbicides Development Programme 301): a phase 3, randomised, double-blind, parallel-group trial. The Lancet, 2010, 376, 1329-1337.

[39] Mitsuya, H.; Popovic, M.; Yarchoan, R.; Matsushita, S.; Gallo, R. C.; Broder, S. Suramin protection of T cells in vitro against infectivity and cytopathic effect of HTLV-III. Science, 1984, 226, 172174.

[40] (a) Carteau, S.; Mouscadet, J.F.; Goulaouic, H.; Subra, F.; Auclair, C. Inhibitory effect of the polyanionic drug Suramin on the in vitro HIV DNA integration reaction. Arch. Biochem. Biophys., 1993, 305, 606-610. (b) De Clercq, E. Suramin in the treatment of AIDS: mechanism of action. Antiviral Res., 1987, 7(1), 1-10.

[41] Yahi, N.; Sabatier, J.-M.; Nickel, P.; Mabrouk, K.; Gonzalez-Scarano, F.; Fantini, J. Suramin Inhibits Binding of the V3 Region of HIV-1 Envelope Glycoprotein a120 to Galactosylceramide, the Receptor for HIV-1 gp120 on Human Colon Epithelial Cells. J. Biol. Chem., 1994, 269, 2434924353

[42] Levine, A.M.; Gill, P.S.; Cohen, J.; Hawkins, J.G.; Formenti, S.C.; Aguilra, S.; Meyer, P.R.; Krailo, M.; Parker, J.; Rasheed, S. Suramin antiviral therapy in the acquired immunodeficiency syndrome: clinical, immunologic, and virologic results. Ann. Intern. Med., 1986, 105, 32-37.

[43] (a) Ono, M.; Wada, Y.; Wu, Y.; Nemori, R.; Jinbo, Y.; Wang, H.; Lo, K.-M.; Yamaguchi, N.; Brunkhorst, B.; Otomo, H.; Wesolowski, J.; Way, J.C.; Itoh, I.; Gillies, S.; Chen, L.B. FP-21399 blocks HIV envelope protein-mediated membrane fusion and concentrates in lymph nodes. Nat. Biotechnol., 1997, 15, 343-348; (b) Zhang, J.L.; Choe, H.; Dezube, B.J.; Farzan, M.; Sharma, P.L.; Zhou, X.C.; Chen, L.B.; Ono, M.; Gillies, S.; Wu, Y.; Sodroski, J.G.; Crumpacker, C.S. The BisAzo Compound FP-21399 Inhibits HIV-1 Replication by Preventing Viral Entry. Virology, 1998, $244,530-541$.

[44] (a) Dezube, B.J.; Dahl, T.A.; Wong, T.K.; Chapman, B.; Ono, M.; Yamaguchi, N.; Gillies, S.D.; Chen, L.B.; Crumpacker, C.S. A Fusion Inhibitor (FP-21399) for the Treatment of Human Immunodeficiency Virus Infection: A Phase I Study. J. Infect. Dis., 2000, 182, 607-610; (b) Poli, G.; Vicenzi, E. FP-21399 (Lexigen Pharmaceuticals). IDrugs, 2001, 4, 1293-1295. 
[45] Debnath, A.K.; Radigan, L.; Jiang, S. Structure-Based Identification of Small Molecule Antiviral Compounds Targeted to the gp41 Core Structure of the Human Immunodeficiency Virus Type 1. J. Med. Chem., 1999, 42, 3203-3209.

[46] (a) Wang, H.; Qi, Z.; Guo, A.; Mao, Q.; Lu, H.; An, X.; Xia, C.; Li, X.; Debnath, A.K.; Wu, S.; Liu, S.; Jiang, S. ADS-J1 Inhibits Human Immunodeficiency Virus Type 1 Entry by Interacting with the gp41 Pocket Region and Blocking Fusion-Active gp41 Core Formation. Antimicrob. Agents Chemother., 2009, 53, 4987-4998; (b) Armand-Ugón, M.; Clotet-Codina, I.; Tintori, C.; Manetti, F.; Clotet, B.; Botta, M.; Esté, J.A. The anti-HIV activity of ADS-J1 targets the HIV-1 gp120. Virology, 2005, 343, 141-149.

[47] González-Ortega, E.; Mena, M.-P.; Permanyer, M.; Ballana, E.; Clotet, B.; Esté, J.A. ADS-J1 Inhibits HIV-1 Entry by Interacting with gp120 and Does Not Block Fusion-Active gp41 Core Formation. Antimicrob. Agents Chemother., 2010, 54, 4487-4492.

[48] Watanabe, K.; Negi, S.; Sugiura, Y.; Kiriyama, A.; Honbo, A.; Iga, K.; Kodama, E. N.; Naitoh, T.; Matsuoka, M.; Kano, K. Binding of Multivalent Anionic Porphyrins to V3 Loop Fragments of an HIV-1 Envelope and Their Antiviral Activity. Chem. Asian J., 2010, 5, 825-834.

[49] Saito, S.; Furumoto, T.; Ochiai, M.; Hosono, A.; Hosono, H.; Haraguchi, U.; Ikeda, R.; Shimada, N. Synthetic studies on the relationship between anti-HIV activities and micelle forming abilities of various alkylated glycyrrhetinate diglycoside sodium sulfates and related compounds. Eur. J. Med. Chem., 1996, 31, 365-381.

[50] Schols, D.; Baba, M.; Pauwels, R.; Desmyter, J.; De Clercq, E. Specific interaction of Aurintricarboxylic acid with the human immunodeficiency virus/CD4 cell receptor. Proc. Natl. Acad. Sci. USA, 1989, 86, 3322-3326.

[51] (a) Cushman, M.; Wang, P.; hang, S.H.; Wild, C.; De Clercq, E.; Schols, D.; Goldman, M.E.; Bowen, J.A. Preparation and anti-HIV activities of Aurintricarboxylic acid fractions and analogues: direct correlation of antiviral potency with molecular weight. J. Med. Chem., 1991, 34, 329-337. (b) Cushman, M.; Kanamathareddy, S.; De Clercq, E.; Schols, D.; Goldman, M.E.; Bowen, J.A. Synthesis and anti-HIV activities of low molecular weight Aurintricarboxylic acid fragments and related compounds. J. Med. Chem., 1991, 34, 337-342.

[52] Balzarini, J. Targeting the glycans of gp120: a novel approach aimed at the Achilles heel of HIV. Lancet Infect. Dis., 2005, 5, 726-731.

[53] (a) Balzarini, J.; Van Laethem, K.; Hatse, S.; Vermeire, K.: De Clercq, E.; Peumans, W.; Van Damme, E.; Vandamme, A.-M.; Bolmstedt, A.; Schols, D. Profile of resistance of human immunodeficiency virus to mannose-specific plant lectins. J. Virol., 2004, 78, 10617-10627. (b) Balzarini, J.; Van Laethem, K.; Hatse, S.; Froeyen, M.; Van Damme, E.; Bolmstedt, A.; Peumans, W.; De Clercq, E.; Schols, D. Marked depletion of glycosylation sites in HIV-1 gp120 under selection pressure by the mannose-specific plant lectins of Hippeastrum hybrid and Galanthus 
nivalis. Mol. Pharmacol., 2005, 67, 1556-1565. (c) Balzarini, J.; Van Laethem, K.; Hatse, S.; Froeyen, M.; Peumans W.; Van Damme, E.; Schols D. Carbohydrate-binding Agents Cause Deletions of Highly Conserved Glycosylation Sites in HIV gp120: a new therapeutic concept to hit the achilles heel of HIV. J. Biol. Chem., 2005, 280, 41005-41014; (d) Balzarini, J.; Van Laethem, K.; Peumans, W.J.; Van Damme, E.J.; Bolmstedt, A.; Gago, F.; Schols, D. Mutational pathways, resistance profile, and side effects of Cyanovirin relative to human immunodeficiency virus type 1 strains with $N$-glycan deletions in their gp120 envelopes. J. Virol., 2006, 80, 8411-8421. (e) Witvrouw, M.; Fikkert, V.; Hantson, A.; Pannecouque, C.; O’Keefe, B.R.; McMahon, J.; Stamatatos, L.; De Clercq, E.; Bolmstedt, A. Resistance of human immunodeficiency virus type 1 to the high-mannose binding agents Cyanovirin $\mathrm{N}$ and Concanavalin A. J. Virol., 2005, 79, 7777-7784.

[54] Reitter, J.N.; Means, R.E.; Desrosiers, R.C. A role for carbohydrates in immune evasion in AIDS. Nat. Med., 1998, 4, 679-684.

[55] Banerjee, K.; Michael, E.; Eggink, D.; van Montfort, T.; Lasnik, A.B.; Palmer, K.E.; Sanders, R.W.; Moore, J.P.; Klasse, P.J. Occluding the Mannose Moieties on Human Immunodeficiency Virus Type 1 gp120 with Griffithsin Improves the Antibody Responses to Both Proteins in Mice. AIDS Res. Human Retrovir., 2012, 28 (2), 206-214.

[56] Auwerx J.; François K.O.; Covens K.; Van Laethem K.; Balzarini J. Glycan deletions in the HIV-1 gp120 V1/V2 domain compromise viral infectivity, sensitize the mutant virus strains to carbohydrate-binding agents and represent a specific target for therapeutic intervention. Virology, 2008, 382, 10-19.

[57] Francois, K.O.; Balzarini, J. The highly conserved glycan at asparagine 260 of HIV-1 gp120 is indispensable for viral entry. J. Biol. Chem., 2011, 286, 42900-42910.

[58] Balzarini, J. Targeting the glycans of glycoproteins: a novel paradigm for antiviral therapy. Nat. Rev. Microbiol., 2007, 5, 583-597.

[59] Bertaux, C.; Daelemans, D.; Meertens, L.; Cormier, E.G.; Reinus, J.F.; Peumans, W.J.; Van Damme, E.J.; Igarashi, Y.; Oki, T.; Schols, D.; Dragic, T.; Balzarini, J. Entry of Human Immunodeficiency Virus Type 1 and Hepatitis C Virus is Selectively Inhibited by Carbohydrate-Binding Agents but not by Polyanions. Virology, 2007, 366, 40-50.

[60] A series of excellent extended reviews onthe structural and biological properties of CBPs have been recently published: (a) Francois, K.O.; Balzarini, J., Potential of carbohydrate-binding agents as therapeutics against enveloped viruses, Med. Res. Rev. 2012, 32, 349-387. (b) Huskens, D.; Schols, D. Algal Lectins as Potential HIV Microbicide Candidates. Mar. Drugs, 2012, 10, 1476-1497. (c) Balzarini, J. Inhibition of HIV entry by carbohydrate-binding proteins. Antivir. Res., 2006, 71, $237-$ 247. (d) Botos, I.; Wlodawer, A. Proteins that bind high-mannose sugars of the HIV envelope. Prog. Biophys. Mol. Biol., 2005, 88, 233-282. 
[61] (a) Buffa, V.; Stieh, D.; Mamhood, N.; Hu, Q.; Fletcher, P.; Shattock, R.J. Cyanovirin-N potently inhibits human immunodeficiency virus type 1 infection in cellular and cervical explant models. $J$. General Virol., 2009, 90, 234-243. (b) Xiong, S.; Fan, J.; Kitazato, K., The antiviral protein Cyanovirin-N: the current state of its production and applications. Appl. Microbiol. Biotechnol., 2010, 86, 805-812.

[62] (a) Tsai; C.C.; Emau, P.; Jiang, Y. H.; Agy, M.B.; Shattock, R.J.; Schmidt, A.; Morton, W.R.; Gustafson, K.R.; Boyd, M.R. Cyanovirin-N inhibits AIDS virus infections in vaginal transmission models. AIDS Res. Hum. Retroviruses, 2004, 20, 11-18. (b) Tsai, C.C.; Emau, P.; Jiang, Y.; Tian, B.; Morton, W.R.; Gustafson, K.R.; Boyd, M.R. Cyanovirin-N gel as a topical microbicide prevents rectal transmission of SHIV89.6P in macaques. AIDS Res. Hum. Retroviruses, 2003, 19, 535-541.

[63] (a) Gustafson, K.R.; Sowder II, R.C.; Henderson, L.E.; Cardellina II, J.H.; McMahon, J.B.; Rajamani, U.; Pannell, L.K.; Boyd, M.R. Isolation, primary sequence determination, and disulfide bond structure of Cyanovirin-N, an anti-HIV (human immunodeficiency virus) protein from the cyanobacterium Nostoc ellipsosporum. Biochem. Biophys. Res. Commun., 1997, 238, 223-228. (b) Boyd, M.R.; Gustafson, K.R.; McMahon, J.B.; Shoemaker, R.H.; O’Keefe, B.R.; Mori, T.; Gulakowski, R.J.; Wu, L.; Rivera, M.I.; Laurencot, C.M.; Currens, M.J.; Cardellina II, J.H.; Buckheit, R.W.; Nara, P.L.; Pannell, L.K.; Sowder II, R.C.; Henderson, L.E. Discovery of Cyanovirin-N, a Novel Human Immunodeficiency Virus-Inactivating Protein That Binds Viral Surface Envelope Glycoprotein gp120: Potential Applications to Microbicide Development. Antimicrob. Agents Chemother., 1997, 41, 1521-1530.

[64] (a) Botos, I.; O'Keefe, B.R.; Shenoy, S.R.; Cartner, L.K.; Ratner, D.M.; Seeberger, P.H.; Boyd, M.R.; Wlodawer, A. Structures of the complexes of a potent anti-HIV protein Cyanovirin-N and high mannose oligosaccharides. J. Biol. Chem., 2002, 277, 34336-34342. (b) Botos, I.; Wlodawer, A., Cyanovirin-N: a sugar-binding antiviral protein with a new twist. Cell. Mol. Life Sci., 2003, 60, 277-287.

[65] Huskens, D.; Vermeire, K.; Vanderneulebroucke, E.; Balzarini, J.; Schols, D. Safety concerns for the potential use of Cyanovirin-N as a microbicidal anti-HIV agent. Int. J. Biochem. Cell. Biol., 2008, 40, 2802-2814.

[66] Buffa, V., Stieh, D.; Manhood, N.; Hu, Q.; Fletcher, P.; Shattock R.J. Cyanovirin-N potently inhibits human immunodeficiency virus type 1 infection in cellular and cervical explant models. J. Gen. Virol., 2009, 90, 234-243.

[67] Kerh, J.C.; Zilliges, Y.; Springer, A. Disney, M.D.; Ratner, D.D.; Bouchier, C.; Seeberger, P.H.; de Marsac, N.T.; Dittmann, E. A mannan binding lectin is involved in cell-cell attachment in a toxic strain of Microcystis auriginosa. Mol. Microbiol., 2006, 59, 893-906.

[68] (a) Huskens, D.; Férir; G.; Vermeire, K.; Kehr, J.-C.; Balzarini, J.; Dittmann, E.; Schols, D.

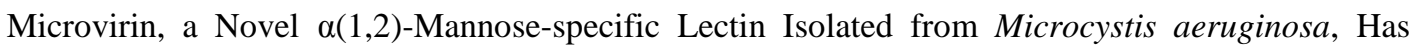


Anti-HIV-1 Activity Comparable with That of Cyanovirin-N but a Much Higher Safety Profile. $J$. Biol. Chem., 2010, 285,24845-24854. (b) Shahzad-ul-Hussan, S.; Gustchina, E.; Ghirlando, R.; Clore, G.M.; Bewley, C.A. Solution Structure of the Monovalent Lectin Microvirin in Complex with Mana(1-2)Man Provides a Basis for Anti-HIV Activity with Low Toxicity. J. Biol. Chem., 2011, 286, 20788-20796.

[69] Mori, T.; O’Keefe, B.R.; Sowder, R.C.; Bringans, S.; Gardella, R.; Berg, S.; Cochran, P.; Turpin, J. A.; Buckheit, R.W., Jr.; McMahon, J.B.; Boyd, M.R. Isolation and characterization of Griffithsin, a novel HIV-inactivating protein, from the red alga Griffithsia sp. J. Biol. Chem., 2005, 280, 93459353.

[70] (a) Ziolkowska, N.E.; O’Keefe, B.R.; Mori, T.; Zhu, C.; Giomarelli, B.; Vojdani, F.; Palmer, K.E.; McMahon, J.B.; Wlodawer, A. Domain-swapped structure of the potent antiviral protein Griffithsin and its mode of carbohydrate binding. Structure, 2006, 14, 1127-1135. (b) Ziolkowska, N.E.; Wlodawer, A. Structural studies of algal lectins with anti-HIV activity. Acta Biochim. Pol., 2006, $53,617-626$.

[71] Férir, G.; Palmer, K. E.; Schols, D. Synergistic activity profile of Griffithsin in combination with Tenofovir, Maraviroc and Enfuvirtide against HIV-1 clade C. Virology, 2011, 417, 253-258.

[72] Férir, G.; Huskens, D.; Palmer, K.E.; Boudreaux, D.M.; Swanson, M.D.; Markovitz, D.M.; Balzarini, J.; Schols, D. Combinations of Griffithsin with Other Carbohydrate-Binding Agents Demonstrate Superior Activity Against HIV Type 1, HIV Type 2, and Selected Carbohydrate-Binding AgentResistant HIV Type 1 Strains. AIDS Res. Hum. Retroviruses, 2012, 28(11), 1513-1523.

[73] (a) O’Keefe, B.R.; Vojdani, F.; Buffa, V.; Shattock, R.J.; Montefiori, D.C.; Bakke, J.; Mirsalis, J.; d'Andrea, A.L.; Hume, S.D.; Bratcher, B.; Saucedo, C.J.; McMahon, J.B.; Pogue, G.P.; Palmer, K.E. Scaleable manufacture of HIV-1 entry inhibitor Griffithsin and validation of its safety and efficacy as a topical microbicide component. Proc. Natl. Acad. Sci. USA, 2009, 106, 6099-6104. (b) Emau, P.; Tian, B.; O’Keefa, B.R.; Mori T.; McMahon, J.B.; Palmer, K.E.; Jiang, Y.; Bekele, G.; Tsai, C.C. Griffithsin, a potent HIV entry inhibitor, is an excellent candidate for anti-HIV microbicide. J. Med. Primatol., 2007, 36, 244-253.

[74] Xue, J.; Gao, Y.; Hoorelbeke, B.; Kagiampakis, I.; Zhao, B.; Demeler, B.; Balzarini, J.; LiWang, P.J. The Role of Individual Carbohydrate-Binding Sites in the Function of the Potent Anti-HIV Lectin Griffithsin. Mol. Pharmaceutics, 2012, 9(9), 2613-2625.

[75] Micewicz, E.D.; Cole, A.L.; Jung, C.-L.; Luong, H.; Phillips, M.L.; Pratikhya, P.; Sharma, S.; Waring, A.J.; Cole, A.M.; Ruchala, P. Grifonin-1: A Small HIV-1 Entry Inhibitor Derived from the Algal Lectin, Griffithsin. PLoS One, 2010, 5, e14360.

[76] (a) Davis, A.P. Synthetic lectins. Org. Biomol. Chem., 2009, 7, 3629-3638. (b) Mazik, M. Molecular recognition of carbohydrates by acyclic receptors employing noncovalent interactions. Chem. Soc. Rev., 2009, 38, 935-956. 
[77] (a) Davis, A.P.; James, T.D. In: Functional Synthetic Receptors, Schrader, T.; Hamilton, A.D. ed. Wiley-VCH, Weinheim, Germany, 2005, pp. 45-109. (b) Davis A.P.; Wareham, R.S. Carbohydrate recognition through noncovalent interactions: a challenge for biomimetic and supramolecular chemistry. Angew. Chem. Int. Ed., 1999, 38, 2979-2996. (c) Penedés, S.; Host-Guest Chemistry: Mimetic Approaches to Study the Carbohydrate Recognition. Top. Curr. Chem., Springer-Verlag, Berlin; 2002, vol. 218.

[78] Oki, T.; Tomatsu, K.; Tomita, K.; Saitoh, K.; Tsunakawa, M.; Nishio, M.; Miyaki, T.; Kawaguchi, H. Pradimicin, a novel class of potent antifungal antibiotic. J. Antibiot., 1988, 41, 1701-1704.

[79] Balzarini, J.; Van Laethem, K.; Daelemans, D.; Hatse, S.; Bugatti, A.; Rusnati, M.; Igarashi, Y.; Oki, T.; Schols, D. Pradimicin A, a Carbohydrate-Binding Nonpeptidic Lead Compound for Treatment of Infections with Viruses with High Glycosylated Envelopes, Such as Human Immunodeficiency Virus. J. Virol., 2007, 81, 362-373.

[80] Nakagawa, Y.; Takashi, D.; Takegoshi, K.; Igarashi, T.; Ito, Y. Solid-state NMR analysis of calcium and D-mannose binding of BMY-28864, a water-soluble analogue of Pradimicin A. Bioorg. Med. Chem. Lett., 2012, 23, 1040-1043.

[81] (a) Nakagawa, Y.; Masuda, Y.; Yamada, K.; Doi, T.; Takegoshi, K.; Igarashi, Y.; Ito, Y., Solid-State NMR Spectroscopic Analysis of the $\mathrm{Ca}^{2+}$-dependent Mannose Binding of Pradimicin A. Angew. Chem. Int. Ed., 2011, 50, 6084-6088. (b) Nakagawa, Y.; Doi, T.; Masuda, Y.; Takegoshi, K.; Igarashi, Y.; Ito, Y. Mapping of the Primary Mannose Binding Site of Pradimicin A. J. Am. Chem. Soc., 2011, 133, 17485-17493.

[82] Balzarini, J.; François, K.O.; Laethem, K.V.; Hoorelbeke, B.; Renders, M.; Auwerx, J.; Liekens, S.; Oki, T.; Igarashi, Y.; Schols, D. Pradimicin S, a Highly Soluble Nonpeptidic Small-Size Carbohydrate-Binding Antibiotic, Is an Anti-HIV Drug Lead for both Microbicidal and Systemic Use. Antimicrob. Agents Chemother., 2010, 54, 1425-1435.

[83] Shahzad-ul-Hussan, S.; Ghirlando, R.; Dogo-Isonagie, C.I.; Igarashi, Y.; Balzarini, J.; Bewley, C.A. Characterization and Carbohydrate Specificity of Pradimicin S. J. Am. Chem. Soc., 2012, 134, 12346-12349.

[84] François, K.O.; Pannecouque, C.; Auwerx, J.; Lozano, V.; Pérez-Pérez, M.J.; Schols, D.; Balzarini, J. The phthalocyanine prototype derivative Alcian Blue is the first synthetic agent with selective anti-human immunodeficiency virus activity due to its gp120 glycan-binding potential. Antimicrob. Agents Chemother., 2009, 53, 4852-4859.

[85] Lozano, V.; Aguado, L.; Hoorelbeke, B.; Renders, M.; Camarasa, M.-J.; Schols, D.; Balzarini, J.; San-Félix, A.; Pérez-Pérez, M.J. Targeting HIV Entry through Interaction with Envelope Glycoprotein 120 (gp120): Synthesis and Antiviral Evaluation of 1,3,5-Triazines with Aromatic Amino Acids. J. Med. Chem., 2011, 54, 5335-5348. 
[86] (a) Kiessling, L.L.; Gestwicki, J.E.; Strong, L.E. Synthetic multivalent ligands in the exploration of cell-surface interactions. Curr. Opin. Chem. Biol., 2000, 4, 696-703.

[87] Lis, H.; Sharon, N. Lectins: carbohydrate-specific proteins that mediate cellular recognition. Chem. Rev., 1998, 98, 637-674.

[88] For reviews on boronic acid based receptors, see: (a) James, T.D.; Sandanayake, K.R.A.S.; Shinkai, S. Boronic acid-based molecular receptors. Angew. Chem., Int. Ed. Engl., 1996, 35, 1910-1922. (b) James, T.D.; Shinkai, S. Artificial receptors as chemosensors for carbohydrates. Top. Curr. Chem., 2002, 218, 159-200. (c) James, T.D.; Phillips, M.D.; Shinkai, S. In: Boronic Acids in Saccharide Recognition, RSC, Cambridge, 2006. (d) Jin, S.; Cheng, Y.; Reid, S.; Li, M.; Wang, B. Carbohydrate Recognition by Boronolectins, Small Molecules, and Lectins. Med. Res. Rev., 2010, 30, 171-257; (e) Striegler, S. Selective carbohydrate recognition by synthetic receptors in aqueous solution. Curr. Org. Chem., 2003, 7, 81-102.

[89] Todd A.H. Developing High-Affinity Boron-Based Receptors for Cell-Surface Carbohydrates. ChemBioChem., 2010, 11, 954-957.

[90] Jay, J.I.; Lai, B.E.; Myszka, D.G.; Mahalingam, A.; Langheinrich, K.; Katz, D.F.; Kiser, P.F. Multivalent Benzoboroxole Functionalized Polymers as gp120 Glycan Targeted Microbicide Entry Inhibitors. Mol. Pharmaceutics, 2010, 7, 116-129.

[91] Mahalingam, A.; Geonnotti, A.R.; Balzarini, J.; Kiser, P.F. Activity and Safety of Synthetic Lectins Based on Benzoboroxole-Functionalized Polymers for Inhibition of HIV Entry. Mol. Pharmaceutics, 2011, 8, 2465-2475.

[92] Moebius, U.; Clayton, L.K.; Abraham, S.; Harrison, II, S.C.; Reinherz, E.L. The Human Immunodeficiency Virus gp120 Binding Site on CD4: Delineation by Quantitative Equilibrium and Kinetic Binding Studies of Mutants in Conjunction with a High-Resohtion CD4 Atomic Structure. $J$. Exp. Med., 1992, 176, 507-517.

[93] Fisher, R.A.; Bertonis, J.M.; Meier, W.; Johnson, V.A.; Costopoulos, D.S.; Liu, T.; Tizard, R.; Walker, B.D.; Hirsch, M.S.; Schooley, R.T.; Flavell, R.A. HIV infection is blocked in vitro by recombinant soluble CD4. Nature, 1988, 331, 76-78.

[94] Daar, E.S.; Li, X.L.; Moudgil, T.; Ho, D.D. High concentrations of recombinant soluble CD4 are required to neutralize primary human immunodeficiency virus type 1 isolates. Proc. Natl. Acad. Sci. USA, 1990, 87, 6574-6578.

[95] (a) Allaway, G.P., Davis-Bruno, K.L.; Beaudry, G.A.; Garcia, E.B.; Wong, E.L.; Ryder, A.M.; Hasel, K.W.; Gauduin, M.C.; Koup, R.A.; McDougal, J.S.; Maddon. P.J. Expression and characterization of CD4-IgG2, a novel heterotetramer that neutralizes primary HIV type 1 isolates. AIDS Res. Hum. Retroviruses, 1995, 11, 533-539. (b) Jacobson, J.M.; Israel, R.J.; Lowy, I.; Ostrow, N.A.; Vassilatos, L.S.; Barish, M.; Tran, D.N.H.; Sullivan, B.M.; Ketas, T.J.; O’Neill, T.J.; 
Nagashima, K.A.; Huang, W.; Petropoulos, C.J.; Moore, J.P.; Maddon, P.J.; Olson, W.C. Treatment of Advanced Human Immunodeficiency Virus Type 1 Disease with the viral Entry Inhibitor PRO 542. Antimicrob. Agents Chemother., 2004, 48, 423-429.

[96] For examples see: (a) Cerutti, N.; Mendelow, B.V.; Napier, G.B.; Papathanasopoulos, M.A.; Killick, M.; Khati, M.; Stevens, W.; Capovilla, A. Stabilization of HIV-1 gp120-CD4 Receptor Complex through Targeted Interchain Disulfide Exchange. J. Biol. Mol., 2010, 285, 25743-25752. (b) Martin, L.; Stricher, F.; Misse, D.; Sironi, F.; Pugniere, M.; Barthe, P.; Prado-Gotor, R.; Freulon, I.; Magne, X.; Roumestand, C.; Menez, A.; Lusso, P.; Veas, F.; Vita, C. Rational design of a CD4 mimic that inhibits HIV-1 entry and exposes cryptic neutralization epitopes. Nat. Biotechnol., 2003, 21, 71-76.

[97] (a) Wang, T.; Zhang, Z.; Wallace, O.B.; Deshpande, M.; Fang, H.; Yang, Z.; Zadjura, L.M.; Tweedie, D.L.; Huang, S.; Zhao, F.; Ranadive, S.; Robinson, B.S.; Gong, Y.-F.; Ricardi, K.; Spicer, T.P.; Deminie, C.; Rose, R.; Heidi Wang, H.-G.; Blair, W.S.; Shi, P.-Y.; Lin, P.-F.; Colonno, R.J.; Meanwell, N.A. Discovery of 4-Benzoyl-1-[(4-methoxy-1Hpyrrolo[2,3-b]pyridin-3-yl)oxoacetyl]-2(R)-methylpiperazine (BMS-378806): A Novel HIV-1 Attachment Inhibitor That Interferes with CD4-gp120 Interactions. J. Med. Chem., 2003, 46, 4236-4239. (b) Wang; T.; Yin, Z.; Zhang, Z.; Bender, J.A.; Yang, Z.; Johnson, G.; Yang, Z.; Zadjura, L.M.; D’Arienzo, C.J.; DiGiugno Parker, D.; Gesenberg, C.; Yamanaka, G.A.; Gong, Y.-F.; Ho, H.-T.; Fang, H.; Zhou, N.; McAuliffe, B.V.; Eggers, B.J.; Fan, L.; Nowicka-Sans, B.; Dicker, I.B.; Gao, Q.; Colonno, R.J.; Lin, P.-F.; Meanwell, N.A.; Kadow, J.F. Inhibitors of Human ImmunodeficiencyVirusType 1 (HIV-1)Attachment. 5.AnEvolution from Indole to Azaindoles Leading to the Discovery of 1-(4-Benzoylpiperazin-1-yl)2-(4,7-dimethoxy-1H-pyrrolo[2,3-c]-pyridin-3-yl)ethane-1,2-dione (BMS-488043), a Drug Candidate That Demonstrates Antiviral Activity in HIV-1-Infected Subjects. J. Med. Chem., 2009, $52,7778-7787$.

[98] (a) Wang, J.; Le, N.; Heredia, A.; Song, H.; Redfield, R.; Wang, L.-X. Modification and structureactivity relationship of a small molecule HIV-1 inhibitor targeting the viral envelope glycoprotein gp120. Org. Biomol. Chem., 2005, 3, 1781-1786. (b) Lu, R.-J.; Tucker, J.A.; Zinevitch, T.; Kirichenko, O.; Konoplev, V.; Kuznetsova, S.; Sviridov, S.; Pickens, J.; Tandel, S.; Brahmachary, E.; Yang, Y.; Wang, J.; Freel, S.; Fisher, S.; Sullivan, A.; Zhou, J.; Stanfield-Oakley, S.; Greenberg, M.; Bolognesi, D.; Bray, B.; Koszalka, B.; Jeffs, P.; Khasanov, A.; Ma, Y.-A.; Jeffries, C.; Liu, C.; Proskurina, T.; Zhu, T.; Chucholowski, A.; Li, R.; Sexton, C. Design and Synthesis of Human Immunodeficiency Virus Entry Inhibitors: Sulfonamide as an Isostere for the r-Ketoamide Group. $J$. Med. Chem., 2007, 50, 6535-6544. (c) Lu, R.J.; Tucker, J.A.; Pickens, J.; Ma, Y.-A.; Zinevitch, T.; Kirichenko, O.; Konoplev, V.; Kuznetsova, S.; Sviridov, S.; Brahmachary, E.; Khasanov, A.; Mikel, C.; Yang, Y.; Changhui, L.; Wang, J.; Freel, S.; Fisher, S.; Sullivan, A.; Zhou, J.; Stanfield-Oakley, S.; Baker, B.; Sailstad, J.; Greenberg, M.; Bolognesi, D.; Bray, B.; Koszalka, B.; Jeffs, P.; Jeffries, C.; Chucholowski, A.; Sexton, C. Heterobiaryl Human Immunodeficiency Virus Entry Inhibitors. J. Med. Chem., 2009, 52, 4481-4487. 
[99] Meanwell, N.A.; Wallace, O.B.; Fang, H.; Wang, H.; Deshpande, M.; Wanga, T.; Yin, Z.; Zhang, Z.; Pearce, B.C.; James, J.; Yeung, K.-S.; Qiu, Z.; Wright, J.J.K.; Yang, Z.; Zadjura, L.; Tweedie, D.L.; Yeola, S.; Zhao, F.; Ranadive, S.; Robinson, B.A.; Gong, Y.-F.; Wangd, H.-G. H.; Blair, W.S.; Shi, P.Y.; Colonno, R.J.; Lin, P.-F. Inhibitors of HIV-1 attachment. Part 2: An initial survey of indole substitution patterns. Bioorg. Med. Chem. Lett., 2009, 19, 1977-1981.

[100] Hanna, G.J.; Lalezari, J.; Hellinger, J.A.; Wohl, D.A.; Nettles, R.; Persson, A.; Krystal, M.; Lin, P.; Colonno, R.; Grasela, D.M. Antiviral Activity, Pharmacokinetics, and Safety of BMS-488043, a Novel Oral Small-Molecule HIV-1 Attachment Inhibitor, in HIV-1-Infected Subjects. Antimicrob. Agents Chemother., 2011, 55, 722-728.

[101] Kadow, J.F.; Ueda, Y.; Meanwell, N.; Connolly, T.P.; Wang, T.; Chen, C.-P.; Yeung, K.-S.; Zhu, J.; Bender, J.A.; Yang, Z.; Parker, D.; Lin, P.-F.; Colonno, R.J.; Mathew, M.; Morgan, D.; Zheng, M.; Chien, C.; Grasela, D. Inhibitors of Human Immunodeficiency Virus Type 1 (HIV-1) Attachment 6. Preclinical and Human Pharmacokinetic Profiling of BMS-663749, a Phosphonooxymethyl Prodrug of the HIV-1 Attachment Inhibitor 2-(4-Benzoyl-1-piperazinyl)-1(4,7-dimethoxy-1H-pyrrolo[2,3-c]pyridin-3-yl)-2-oxoethanone (BMS-488043). J. Med. Chem., 2012, 55, 2048-2056.

[102] Guo, Q.; Ho, H.-T.; Dicker, I.; Fan, L.; Zhou, N.; Friborg, J.; Wang, T. McAuliffe, B.V.; Heidi Wang, H.-G.; Rose, R.E.; Fang, H.; Scarnati, H.T.; Langley, D.R.; Meanwell, N.A.; Abraham, R.; Colonno, R.J.; Lin, P.-F. Biochemical and Genetic Characterizations of a Novel Human Immunodeficiency Virus Type 1 Inhibitor That Blocks gp120-CD4 Interactions. J. Virol., 2003, 77, 10528-10536.

[103] Lin, P.-F.; Blair, W.; Wang, T.; Spicer, T.; Guo, Q.; Zhou, N.; Gong, Y.-F.; Wang, H.-G. H.; Rose, R.; Yamanaka, G.; Robinson, B.; Li, C.-B.; Fridell, R.; Deminie, C.; Demers, G.; Yang, Z.; Zadjura, L.; Meanwell, N.; Colonno, R.J. A small molecule HIV-1 inhibitor that targets the HIV-1 envelope and inhibits CD4 receptor binding. Proc. Natl. Acad. Sci. USA, 2003, 100, 11013-11018.

[104] (a) Si, Z.; Madani, N.; Cox, J.M.; Chruma, J.J.; Klein, J.C.; Schön, A.; Phan, N.; Wang, L.; Biorn, A. C.; Cocklin, S.; Chaiken, I.; Freire, E.; Smith III, A. B.; Sodroski, J. G. Small-molecule inhibitors of HIV-1 entry block receptor-induced conformational changes in the viral envelope glycoproteins. Proc. Natl. Acad. Sci. USA, 2004, 101, 5036-3041. (b) Ho, H.-T.; Fan, L.; Nowicka-Sans, B.; McAuliffe, B.; Li, C.-B.; Yamanaka, G.; Zhou, N.; Fang, H.; Dicker, I.; Dalterio, R.; Gong, Y.-F.; Wang, T.; Yin, Z.; Ueda, Y.; Matiskella, J.; Kadow, J.; Clapham, P.; Robinson, J.; Colonno, R.; Lin, P.-F. Envelope Conformational Changes Induced by Human Immunodeficiency Virus Type 1 Attachment Inhibitors Prevent CD4 Binding and Downstream Entry Events. J. Virol., 2006, 80, 4017-4025.

[105] (a) Williams, D.H.; Adam, F.; Fenwick, D.R.; Fok-Seang, J.; Gardner, I.; Hay, D.; Jaiessh, R.; Middleton, D.S.; Mowbray, C.E.; Parkinson, T.; Perros, M.; Pickford, C.; Platts, M.; Randall, A.; Siddle, D.; Stephenson, P.T.; Tran, T.-D.; Vuong, H. Discovery of a small molecule inhibitor 
through interference with the gp120-CD4 interaction. Bioorg. Med. Chem. Lett., 2009, 19, 52465249. (b) Tran, T.-D.; Adam, F.M.; Calo, F.; Fenwick, D.R.; Fok-Seang, J.; Gardner, I.; Hay, D.A.; Perros, M.; Rawal, J.; Middleton, D.S.; Parkinson, T.; Pickford, C.; Platts, M.; Randall, A.; Stephenson, P.T.; Vuong, H.; Williams, D.H. Design and optimisation of potent gp120-CD4 inhibitors, Bioorg. Med. Chem. Lett. 2009, 19, 5250-5255. (c) Middleton, D.S.; Mowbeay, C.E.; Stephenson, P.T.; Williams, D.H. Piperazine derivatives for the treatment of HIV infections, PCT Int. Appl. Patent WO2005016344 A1 20050224. (d) Fenwick, D.R.; Middleton, D.S.; Stephenson, P.T.; Tran, T.-D.; Williams, D.H. Piperazine and Piperidine derivatives as anti-HIV agents, PCT Int. Appl. Patent WO2005121094 A1 20051222.

[106] Caporuscio, F.; Tafi, A.; González, E.; Manetti, F.; Esté, J.A.; Botta, M. A dynamic target-based pharmacophoric model mapping the CD4 binding site on HIV-1 gp120 to identify new inhibitors of gp120-CD4 protein-protein interactions. Bioorg. Med. Chem. Lett., 2009, 19, 6087-6091.

[107] Hurevich, M.; Swed, A.; Joubran, S.; Cohen, S.; Freeman, N.S.; Britan-Rosich, E.; Bardy, M.; Devaux, C.; Kotler, M.; Hoffman, A.; Gilon, C. Rational conversion of noncontinuous active region in proteins into a small orally bioavailable macrocyclic drug-like molecule: The HIV-1 CD4:gp120 paradigm. Bioorg. Med. Chem., 2010, 18, 5754-5761.

[108] Zhao, Q.; Ma, L.; Jiang, S.; Lu, H.; Liu, S.; He, Y.; Strick, N.; Neamati, N.; Debnath, A.K. Identification of $\mathrm{N}$-phenyl-NV-(2,2,6,6-tetramethyl-piperidin-4-yl)-oxalamides as a new class of HIV-1 entry inhibitors that prevent gp120 binding to CD4. Virology, 2005, 339, 213-225.

[109] (a) Schön, A.; Madani, N.; Klein, J.C.; Hubicki, A.; Ng, D.; Yang, X.; Smith III, A.B.; Sodroski, J.; Freire, E. Thermodynamics of Binding of a Low-Molecular-Weight CD4 Mimetic to HIV-1 gp120. Biochemistry, 2006, 45, 10973-10980. (b) Madani, N.; Schön, A.; Princiotto, A.M.; LaLonde, J.M.; Courter, J.R.; Soeta, T.; Ng, D.; Wang, L.; Brower, E.T.; Xiang, S.-H.; Kwon, Y.D.; Huang, C.-C.; Wyatt, R.; Kwong, P.D.; Freire, E.; Smith III, A.B.; Sodroski, J. Small-Molecule CD4 Mimics Interact with a Highly Conserved Pocket on HIV-1 gp120. Structure, 2008, 16, 1689-1701.

[110] (a) Yamada, Y.; Ochiai, C.; Yoshimura, K.; Tanaka, T.; Ohashi, N.; Narumi, T.; Nomura, W.; Harada, S.; Matsushita, S.; Tamamura, H. CD4 mimics targeting the mechanism of HIV entry. Bioorg. Med. Chem. Lett., 2010, 20, 354-358. (b) Narumi, T.; Ochiai, C.; Yoshimura, K.; Harada, S.; Tanaka, T.; Nomura, W.; Arai, H.; Ozaki, T.; Ohashi, N.; Matsushita, S.; Tamamura, H. CD4 mimics targeting the HIV entry mechanism and their hybrid molecules with a CXCR4 antagonist. Bioorg. Med. Chem. Lett., 2010, 20, 5853-5858. (c) Narumi, T.; Arai, H.; Yoshimura, K.; Harada, S.; Nomura, W.; Matsushita, S.; Tamamura, H. Small molecular CD4 mimics as HIV entry inhibitors. Bioorg. Med. Chem., 2011, 19, 6735-6742; (d) LaLonde, J.M.; Elban, M.A.; Courter, J.R.; Sugawara, A.; Soeta, T.; Madani, N.; Princiotto, A.M.; Kwon, Y.D.; Kwong, P.D.; Schön, A.; Freire, E.; Sodroski, J.; Smith, A.B. III. Design, synthesis and biological evaluation of small molecule inhibitors of CD4-gp120 binding based on virtual screening, Bioorg. Med Chem., 2011, 19, 91-101. 
[111] LaLonde, J.M.; Kwon, Y.D.; Jones, D.M.; Sun, A.W.; Courter, J.R.; Soeta, T.; Kobayashi, T.; Princiotto, A.M.; Wu, X.; Schon, A.; Freire, E.; Kwong, P.D.; Mascola, J.R.; Sodroski, J.; Madani, N.; Smith, A.B. III. Structure-based design, synthesis, and characterization of dual hotspot smallmolecule HIV-1 entry inhibitors. J. Med. Chem., 2012, 55, 4382-4396.

[112] Curreli, F.; Choudhury, S.; Pyatkin, I.; Zagorodnikov, V.P.; Bulay, A.K.; Altieri, A.; Kwon, Y.D.; Kwong, P.D.; Debnath, A.K. Design, synthesis, and antiviral activity of entry inhibitors that target the CD4-binding site of HIV-1. J. Med. Chem., 2012, 55, 4764-4775.

[113] Umashankara, M.; McFadden, K.; Zentner, I.; Schön, A.; Rajagopal, S.; Tuzer, F.; Kuriakose, S.A.; Contarino, M.; LaLonde, J.; Freire, E.; Chaiken, I. The Active Core in a Triazol Peptide Dual-Site Antagonist of HIV-1 gp120. ChemMedChem., 2010, 5, 1871-1879.

[114] (a) Baleux, F., Loureiro-Morais, L.; Hersant, Y.; Clayette, P.; Arenzana-Seisdedos, F.; Bonnaffé, D.; Lortat-Jacob, H. A synthetic CD4-heparan sulfate glycoconjugate inhibits CCR5 and CXCR4 HIV-1 attachment and entry. Nat. Chem. Biol., 2009, 5, 743-748. (b) Connell, B.J.; Baleux, F.; Coic, Y.-M.; Clayette, P.; Bonnaffé, D.; Lortat-Jacob, H. A Synthetic Heparan Sulfate-Mimetic Peptide Conjugated to a Mini CD4 Displays Very High Anti-HIV-1 Activity Independently of Coreceptor Usage. Chem. Biol., 2012, 19, 131-139.

[115] Lai, W.; Huang, L.; Ho, P.; Li, Z.; Montefiori, D.; Chen, C.-H. Betulinic Acid Derivatives That Target gp120 and Inhibit Multiple Genetic Subtypes of Human Immunodeficiency Virus Type 1. Antimicrob. Agents Chemother., 2008, 52, 128-136.

[116] Acharya, P.; Dogo-Isonagie, C.; LaLonde, J.M.; Lam, S.N.; Leslie, G.J.; Louder, M.K.; Frye, L.L.; Debnath, A.K.; Greenwood, J.R.; Luongo, T.S.; Martin, L.; Watts, K.S.; Hoxie, J.A.; Mascola, J.R.; Bewley, C.A.; Kwong, P.D. Structure-based identification and neutralization mechanism of tyrosine sulfate mimetics that inhibit HIV-1 entry. ACS Chem. Biol., 2011, 6, 1069-1077.

[117] Seitz, M.; Rusert, P.; Moehle, K.; Trkola, A. Robinson, J.A. Peptidomimetic inhibitors targeting the CCR5-binding site on the human immunodeficiency virus type-1 gp120 glycoprotein complexed to CD4. Chem. Commun., 2010, 46, 7754-7756.

[118] Lingwood, C.A.; Branch, D.R. The role of glycosphingolipids in HIV/AIDS. Discov. Med., 2011, $11,303-313$.

[119] Garg, H.; Francella, N.; Tony, K.A.; Augustine, L.A.; Barchi Jr., J.J.; Fantini, J.; Puri, A.; Mootoo, D.R.; Blumenthal, R. Glycoside analogs of $\beta$-galactosylceramide, a novel class of small molecule antiviral agents that inhibit HIV-1 entry. Antivir. Res., 2008, 80, 54-61.

[120] (a) Doores, K.J.; Burton, D.R. Variable Loop Glycan Dependency of the Broad and PotentHIV-1Neutralizing Antibodies PG9 and PG16. J. Virol., 2010, 84, 10510-10521. (b) Walker, L.M.; Phogat, S.K.; Chan-Hui, P.-Y.; Wagner, D.; Phung, P.; Goss, J.L.; Wrin, T.; Simek, M.D.; Fling, S.; Mitcham, J.L.; Lehrman, J.K.; Priddy, F.H.; Olsen, O.A.; Frey, S.M.; Hammond, P.W.; Kaminsky, 
S.; Zamb, T.; Moyle, M.; Koff, W.C.; Poignard, P.; Burton, D.R. Broad and Potent Neutralizing Antibodies from an African Donor Reveal a New HIV-1 Vaccine Target. Science, 2010, 326, 285289.

[121] Zhang, M.-Y.; Borges, A.R.; Ptak, R.G.; Wang, Y.; Dimitrov, A.S.; Alam, S.M.; Wieczorek, L.; Bouma, P.; Fouts, T.; Jiang, S.; Polonis, V.R.; Haynes, B.F.; Quinnan, G.V.; Montefiori, D.C.; Dimitrov, D.S. Potent and broad neutralizing activity of a single chain antibody fragment against cell-free and cell-associated HIV-1. mAbs, 2010, 2, 266-274.

[122] Chen, W.; Zhu, Z.; Feng, Y.; Dimitrov, D.S. Human domain antibodies to conserved sterically restricted regions on gp120 as exceptionally potent cross-reactive HIV-1 neutralizers. Proc. Natl. Acad. Sci. USA, 2008, 105, 17121-17126.

[123] (a) Parker, C.G.; Domaoal, R.A.; Anderson, K.S.; Spiegel, D.A. An Antibody-Recruiting Small Molecule that Targets HIV gp120. J. Am. Chem. Soc., 2009, 131, 16392-16394. (b) Spiegel, D.; Parker, C. Bifunctional Molecules with Antibody-Recruiting and Entry Inhibitory Activity against the Human Immunodeficiency Virus. PCT Int. Appl. Patent WO 2012068366 A2 20120524.

[124] (a) Vermeire, K.; Schols, D. Cyclotriazadisulfonamides: promising new CD4-targeted anti-HIV drugs. J. Antimicrob. Chemother., 2005, 56, 270-272. (b) Vermeire, K.; Zhang, Y.; Princen, K.; Hatse,S.; Samala, M.; Dey, K.; Choi, H.-J.; Ahn, Y.; Sodoma, A.; Snoeck, R.; Andrei, G.; De Clercq, E.; Bell; T. W.; Schols, D. CADA inhibits human immunodecifiency virus and human herpesvirus 7 replication by down-modulation of the cellular CD4 receptor. Virology, 2002, 302, 342-353. (c) Demillo, V.G.; Goulinet-Mateo, F.; Kim, J.; Schols, D.; Vermeire, K.; Bell, T.W. Unsymmetrical Cyclotriazadisulfonamide (CADA) Compounds as Human CD4 Receptor DownModulating Agents. J. Med. Chem., 2011, 54, 5712-5721.

[125] Vermeire K.; Brouwers, J.; Van Herrewege Y.; Le Grand, R.; Vanham, G.; Augustijns, P.; Bell, T.W.; Schols, D. CADA, a potential anti-HIV microbicide that specifically targets the cellular CD4 receptor. Curr. HIV Res., 2008, 6, 246-56.

[126] For more details on the contribution of oxidoreductases, in particular Trx1, to the mechanism of HIV entry see: Azimi, I.; Matthias, L.J.; Wong, J.W.H.; Hogg, P.J. Disulfide Bond that Constrains the HIV-1 gp120 V3 Domain is Cleaved by Thioredoxin. J. Biol. Chem., 2010, 285, 40072-40080.

[127] Lara, H.H.; Ixtepan-Turrent, L.; Garza-Treviño, E.N.; Flores-Teviño, S.M, Borkow, G.; RodriguezPadilla, C. Antiviral propierties of 5,5' -dithiobis-2-nitrobenzoic acid and bacitracin against T-tropic human immunodeficiency virus type 1. Virol. J., 2011, 8, 137.

[128] Khan, M.M.G.; Simizu, S.; Lai, N.S.; Kawatani, M. Discovery of a Small Molcule PDI Inhibitor that Inhibits Reduction of HIV-1 Envelope Glycoprotein gp120. ACS Chem. Biol., 2011, 6, 245-251. 
[129] Reiser, K.; François, K.O.; Schols, D.; Bergman, T.; Jörnvall, H.; Balzarini, J.; Karlsson, A.; Lundberg, M. Thioredoxin-1 and protein disulfide isomerase catalyze the reduction of similar disulfides in HIV gp120. Int. J. Biochem. Cell Biol., 2012, 44, 556-562. 